Chapter 8

\title{
Cellular and Molecular Mechanisms of Insect Immunity
}

\author{
Carlos Rosales
}

Additional information is available at the end of the chapter

http://dx.doi.org/10.5772/67107

\begin{abstract}
Multicellular organisms constantly encounter potentially harmful microorganisms. Although insects lack an adaptive immune system, they do have powerful means of fighting infections. Cellular responses involve phagocytosis of bacteria and encapsulation of parasites. In addition, insects can mount a humoral response against pathogens. This is characterized by the secretion of antimicrobial peptides into the hemolymph. Recognition of foreign pathogens involves specific receptors for sensing infection. These include peptidoglycan recognition proteins (PGRPs) and $\beta$-glucan recognition proteins ( $\beta$ GRPs). Engagement of these receptors starts signaling pathways that activate the genes that encode antimicrobial peptides. These pathways include the Toll, the Imd, and the JAK-STAT. This chapter describes the innate immunity of insects including both the cellular and humoral responses to bacteria, fungi, and parasites. In addition, recent advances in insect antivirus immune responses are discussed.
\end{abstract}

Keywords: insect, phagocytosis, hemocyte, innate immunity, signal transduction, toll, Imd, JAK/STAT, TLR, siRNA, autophagy

\section{Introduction}

Multicellular organisms are constantly exposed to different microorganisms, many of which can be potentially harmful. To protect themselves from these microorganisms, multicellular organisms have evolved cellular and molecular defense mechanisms against infection. These defense mechanisms are known as immunity. At the beginning of an infection from viruses, bacteria, fungi, and protozoa, early mechanisms such as expression of antimicrobial products, recognition of microorganisms by pattern-recognition receptors (PRRs), and activation of phagocytic cells get engaged for eliminating pathogens. These early mechanisms are collectively known as innate immune systems. In vertebrates, such as mammals, cells facilitate the recognition of microorganisms at later times during the course of an infection with specific 
receptors for microbial antigens. The T- and B-lymphocytes are the cells responsible for the specific recognition of pathogenic antigens and together provide a more selective defense system, known as adaptive immunity, which provides a much better and faster response to the same pathogen during a second challenge.

Insect species live practically in every known habitat and ecological niche, except marine environments. This diversity exposes insects to all sorts of infectious agents. Yet, insects are clearly very successful organisms against infections. Although insects lack an adaptive immune system, they do have a powerful innate immune system for fighting infections. The innate immune system of insects consists of physical barriers, humoral responses, and cellular responses [1, 2].

Physical barriers include the integument and the peritrophic membrane. Integument, the outer surface of an insect, is formed by a single layer of cells covered by a multilayered cuticle [3]. The peritrophic membrane is a layer made of chitin and glycoprotein that covers the insect midgut. It functions as a physical barrier against abrasive food particles and digestive pathogens [4]. However, this membrane is semipermeable and therefore it is not an efficient barrier for viruses. These structures constitute the initial protection for the hemocele (the insect body cavity) and the midgut epithelium against microorganisms. When microorganisms enter these barriers, the humoral and cellular immune responses are activated. Humoral immune responses include production of antimicrobial peptides, activation of prophenoloxidase (proPO), and production of reactive oxygen species [5, 6]. Cellular immune responses include nodulation, encapsulation, and phagocytosis [7, 8].

Hemolymph, the liquid that fills the hemocele, transports nutrients throughout the insect body and also contains several types of free-moving cells or hemocytes. There are several types of hemocytes including granulocytes, plasmatocytes, spherulocytes, and oenocytoids $[7,9]$. However, it is important to emphasize that not all these hemocyte types exist in all insect species [10, 11]. Hemocytes are essential for insect immunity, as shown in Drosophila melanogaster larvae where plasmatocytes, making up approximately $95 \%$ of circulating hemocytes, decrease in numbers during an infection [12]. Also, the genetic [13] or mechanical elimination $[14,15]$ of phagocytic hemocytes in adult Drosophila leads to an increase in infection susceptibility from various bacteria.

Upon infection of the hemocele, cellular immune responses are engaged almost immediately; while humoral responses take place several hours later. It is believed that invading microorganisms are first eliminated by hemocytes and later the humoral responses finish up the few microorganisms not eliminated by cells [16]. These defense mechanisms do not work independently from each other. For example, hemocytes produce molecules that promote hemocyte-microorganism interactions $[17,18]$. These molecules function similarly to the opsonins (complement and antibodies) that increase phagocytosis of microorganisms by leukocytes [19]. Also, Drosophila plasmatocytes induce fat-body (insect equivalent of the liver) cells to produce antimicrobial peptides after a bacterial infection [14]. In addition, in adult flies, plasmatocytes contribute to reduce the infection susceptibility to various bacteria including Escherichia coli, Bacillus subtilis, and importantly Staphylococcus aureus $[13,15]$. These findings clearly indicate that there is an effective cross-talk between humoral and cellular immunity in insects. 
Here, I will describe insect cellular immune functions with emphasis on the innate immunity of insects including both the cellular and humoral responses to bacteria, fungi, and parasites. Specific receptors for sensing infection and the signaling pathways that activate genes for production of antimicrobial peptides will be described. In addition, recent advances in insect antivirus immune responses are discussed.

\section{The inducible humoral response}

One of the first identified defense mechanisms of insects is the production of antimicrobial peptides (AMPs). Upon microbial infection, a series of small peptides and proteins are produced and released into the hemolymph [20]. The production of AMPs is highly inducible following a microbial infection, the levels of AMPs change from mostly undetectable in uninfected animals to micromolar concentrations in hemolymph of infected individuals [21]. Expression of these AMPs comes mainly from fat-body although hemocytes also contribute to their production $[5,22]$. The first identified antimicrobial protein of insects was the lysozyme from Galleria mellonella. This enzyme is structurally similar to the chicken C-type lysozyme [23] and is capable of degrading bacterial cell wall peptidoglycans of Gram-positive bacteria. It also has some activity against Gram-negative bacteria [24, 25] and against some fungi [26].

\subsection{Antimicrobial peptides}

Biochemical analysis of the hemolymph of the fruit-fly D. melanogaster and other Diptera has led to the discovery of seven groups of AMPs in insects. They present a wide variety of actions against microorganisms and can be grouped into three families based on their main biological targets [21]. Against Gram-positive bacteria, there are defensins. Against Gram-negative bacteria, there are cecropins, drosocin, attacins, and diptericin. Against fungi, there are drosomycin and metchnikowin.

\subsubsection{Defensins}

Insect defensins are characterized by having three or four stabilizing intramolecular disulfide bonds. The name comes from their molecular similarity to mammalian $\alpha$ and $\beta$ defensins [27]. Insect defensins form two groups: one with peptides presenting $\alpha$-helix/ $\beta$ sheet mixed structure and the other with peptides presenting triple-stranded antiparallel $\beta$-sheets. Defensins with antibacterial and antifungal activity have been reported in many Lepidopteran species [28-30].

\subsubsection{Cecropins}

Cecropins are small basic peptides of about 31-37 amino acid residues with an amphipathic $\alpha$-helix conformation [27]. The first amphipathic antimicrobial peptide from insects was identified in hemolymph of the silkworm Hyalophora cecropia and was named cecropin [31]. Amphipathic peptides present antimicrobial activity due to their capacity to damage pathogen 
cell membranes; they also inhibit proline uptake and cause leaky membranes. Now, several cecropin family genes from many lepidoptera species are known. In Bomby mori, 13 cecropin genes were found [32]. Moricins are another group of amphipathic $\alpha$-helical antimicrobial peptides [33] found first in the silkworm B. mori. In the B. mori genome nine moricin genes were found [32], and in G. mellonella eight moricin homologs are reported to have activity against bacterial as well as against yeast and filamentous fungi [34]. Cecropins isolated from insects other than $H$. cecropia have been given various names, for example, bactericidin, lepidopterin, and sarcotoxin [21]. However, all of these peptides are structurally related.

\subsubsection{Drosocin}

Drosocin is a 19-mer cationic antimicrobial peptide from D. melanogaster. An O-glycosylated threonine residue has been identified as important for the antimicrobial activity of these peptides, since elimination of the disaccharide at this position renders them with activity several times lower than the native compound [35].

\subsubsection{Attacins}

Attacins are glycine-rich $20 \mathrm{kDa}$ AMPs originally isolated from the hemolymph of $H$. cecropia. Two attacin isoforms, one acid and one basic, have been cloned from H. cecropia [36] and they induce an increase of permeability of the outer-membrane of bacteria, binding mainly to lipopolysaccharide (LPS). This explains why the basic attacin is more effective against E. coli than the acid attacin. Attacins also inhibit outer-membrane protein synthesis of bacteria at the transcriptional level [36]. Attacins have also been cloned from other Lepidoptera such as the beet armyworm, Spodoptera exigua [37].

Gloverins and lebocins are also glycine-rich AMPs found in the lepidoptera [11, 38, 39]. These peptides also inhibit bacterial growth by blocking outer-membrane protein synthesis [40]. In addition to their antibacterial activity, gloverins also present antifungal activity [38, 39], and recently, it has also been reported that they may have antiviral activity [41].

\subsubsection{Diptericin}

Diptericin is an AMPs rich in glycine synthesized by insects in response to a bacterial injection or to injury. It is a basic heat-stable peptide with a molecular weight of $8.6 \mathrm{kDa}$, containing high levels of Asx, Pro, and Gly. It is active only against a limited range of Gram-negative bacteria and seems to function by disrupting the cytoplasmic membrane of growing bacteria [21]. Recently, diptericin has been reported to be involved not only in inhibiting bacterial growth but also in protection from oxidative stress. Authors suggested that diptericin may trap or "scavenge" free radical anions and also attenuate oxygen toxicity by increasing antioxidant enzyme activities in D. melanogaster [42].

\subsubsection{Drosomycin}

Drosomycin is an inducible antifungal peptide of 44 residues initially isolated from bacteriachallenged D. melanogaster. It is synthesized in the fat-body and secreted into the hemolymph 
of the insect. It exhibits potent antifungal activity but is inactive against bacteria. Drosomycin belongs to the cysteine-stabilized $\alpha$-helical and $\beta$-sheet $(\mathrm{CS} \alpha \beta)$ superfamily and is composed of an $\alpha$-helix and a three-stranded $\beta$-sheet stabilized by four disulphide bridges [43]. It also has a significant homology with a family of $5 \mathrm{kDa}$ cysteine-rich plant antifungal peptides isolated from seeds of Brassicaceae [44]. Drosomycin exhibits a narrow antimicrobial spectrum and is only active against some filamentous fungi [45]. However, recent work using recombinant drosomycin expressed in E. coli revealed that it also has antiparasitic and antiyeast activities [46].

\subsubsection{Metchnikowin}

Metchnikowin is a 26-residue proline-rich peptide whose expression in Drosophila is inducible by infection [47]. This peptide is expressed in the fat-body after immune challenge and can be induced either by the Toll or the Imd pathways [48] (described later). The metchnikowin peptide is unique among the Drosophila antimicrobial peptides in that it is active against both Gram-positive bacteria and fungi. Recently, Metchnikowin has been shown to be able to protect a transgenic plant from fungal pathogens. Transgenic barley expressing the metchnikowin gene displayed enhanced resistance to several fungal ascomycetes pathogens, including powdery mildew and Fusarium head blight [49].

\subsection{Signaling pathways activating genes that encode antimicrobial peptides}

Once a microorganism is detected by PRRs, a series of signaling molecules are activated inside cells to instruct them for different responses. These molecules follow particular signaling pathways that determine the final cellular response. In insects, the signaling pathways involved in humoral immune responses are best described in D. melanogaster [50]. The humoral immune responses mainly involve the release of AMPs by the fat-body, via the Toll [51, 52], the immune deficiency (Imd) [53, 54], and the JAK-STAT [55] pathways. Gram-positive bacteria and fungi predominantly induce the Toll signaling pathway, whereas Gramnegative bacteria activate the Imd pathway.

\subsubsection{The Toll pathway}

The Toll pathway was initially identified as a developmental pathway in D. melanogaster. It involves signaling to nuclear factor kappa B (NF- $\mathrm{kB})$ and is essential for embryonic development and immunity $[51,56]$. The study of this pathway leads to the subsequent characterization of Toll-like receptors (TLRs) and using this it has reshaped our understanding of the mammalian immune system $[57,58]$. Activation of the transmembrane receptor Toll requires a proteolytically cleaved form of an extracellular cytokine-like polypeptide, Spätzle [59], suggesting that Toll requires cooperation of other PRRs. This idea is supported by the fact that a mutation in a peptidoglycan recognition protein (PGRP-SA) blocks Toll activation by Gram-positive bacteria and significantly decreases resistance to this type of infection [60]. Toll activation is not only mediated by PGRPs, but it requires Gram-negative binding protein (GNBP) 1 for Gram-positive bacterial infections [61], and GNBP3 for fungal infections [62]. In addition, the Drosophila Persephone protease activates the Toll pathway when proteolytically matured by secreted fungal virulence factors [63] (Figure 1). 


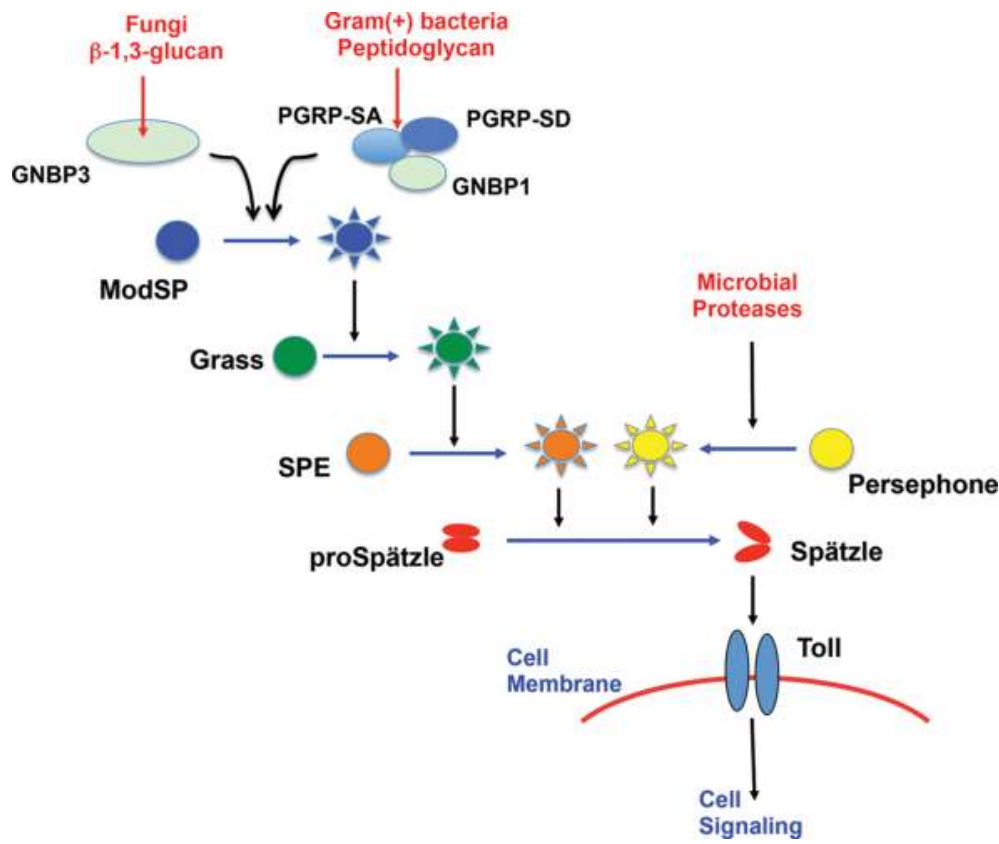

Figure 1. Protease cascades important for Toll activation. The Toll ligand Spätzle is formed when proSpätzle is cleaved by serine protease cascades. The fungi cell wall component $\beta-1,3$-glucan is recognized by the circulating pathogen recognition receptor Gram-negative binding protein 3 (GNBP3); while the receptors peptidoglycan recognition proteins PGRP-SA and PGRP-SD, together with GNBP1, recognize peptidoglycan of Gram-positive bacteria. These interactions initiate protease cascades that converge at the level of the serine protease ModSP, which then activates the protease Grass, which in turn activates the Spätzle processing enzyme (SPE). Some microbial proteases (virulence factors) released from pathogenic fungi or bacteria can also be detected by the protease Persephone. Cleavage of Persephone leads to activation of SPE and formation of active Spätzle. Horizontal blue arrows represent proteolytic conversion of the proenzymes (circles) into their active forms (stars). Vertical black arrows represent the site of action for the active proteases.

Toll signaling is activated when cleaved Spätzle binds the Toll receptor. This binding triggers dimerization of the intracytoplasmic TIR domains, inducing binding of the adaptor protein MyD88 through its own TIR domain. MyD88 binds the adaptor protein Tube, which in turn recruits the protein kinase Pelle. These interactions take place via contact of death domains in each protein. Recruitment of Pelle induces its autophosphorylation, triggering phosphorylation and degradation of cactus (an I $\kappa$ B inhibitor) and translocation to the nucleus of the NF- $\kappa \mathrm{B}$ transcription factors Dorsal and Dif depending on the context [51, 52, 64, 65] (Figure 2).

\subsubsection{The Imd pathway}

The D. melanogaster Imd (immunodeficiency) pathway was discovered when adult flies carrying this mutation alone had impaired production of most AMPs after infection with E. coli and Micrococcus luteus. In these flies, however, the antifungal Drosomycin remained inducible [66]. It was later shown that Drosomycin induction, after fungal infection, was regulated by the Toll pathway, while the response to most Gram-negative bacteria was blocked by the Imd mutation [67]. The Imd pathway is activated when the receptors peptidoglycan 
recognition protein (PGRP)-LC and PGRP-LE bind meso-diaminopimelic acid (DAP)-type peptidoglycan $[68,69]$, which comprises the cell wall of most Gram-negative bacteria. These receptors initiate signaling to the NF- $\kappa \mathrm{B}$ transcription factor Relish [70], via the Fas-associated protein with death domain (FADD) - death-related ced-3/Nedd2-like protein (DREDD), and the transforming growth factor beta (TGF- $\beta$ )-activated kinase 1 (TAK1)-inhibitor of $\kappa B$ kinase (IKK) pathways [53, 68, 71] (Figure 3). Once bound to peptidoglycan, these receptors likely dimerize and connect to the adaptor protein Imd [72]. Imd recruits dFADD (Drosophila FADD) [73] and the DREDD caspase [74]. DREDD cleaves Imd, which is then further activated by K63-ubiquitination via the ubiquitination machinery component inhibitor of apoptosis 2 (IAP2) [75]. The K63-polyubiquitin chains are thought, recruit, and activate TAK1 via the ubiquitin-binding domain of its regulatory partner TAK1-associated binding protein 2 (TAB2). TAK1 is then responsible for activating the IKK complex to allow free Relish to translocate into the nucleus. DREDD is also required for mediating the cleavage of the precursor Relish [76] (Figure 3).

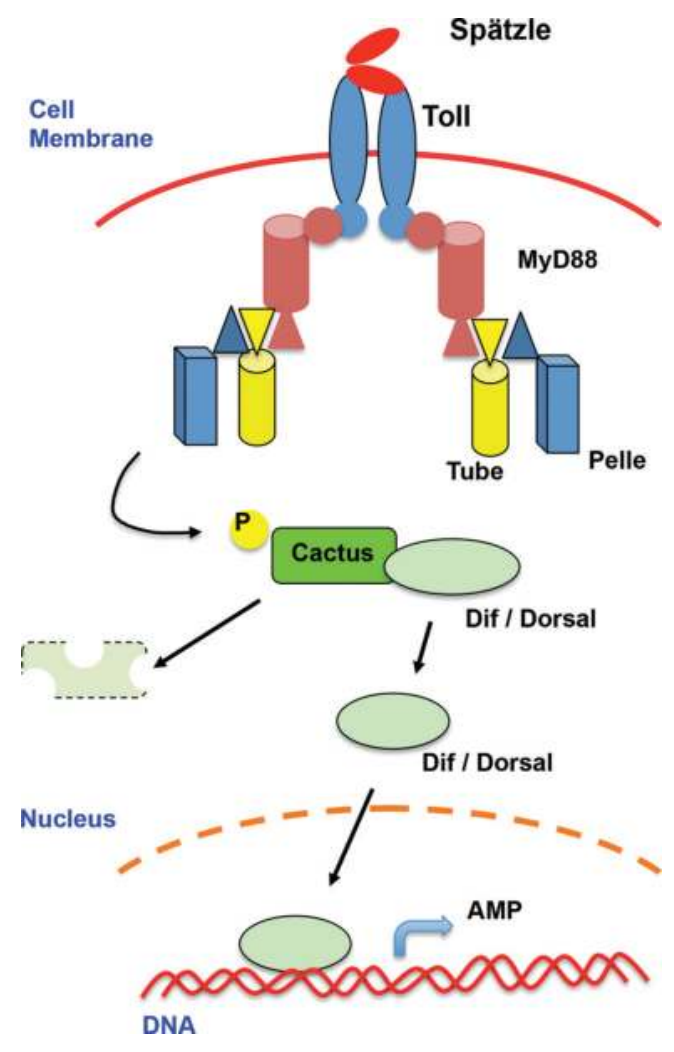

Figure 2. The Toll signaling pathway. Activation of the transmembrane receptor Toll requires a proteolytically cleaved form of Spätzle. Upon Spätzle recognition by a dimer of Toll molecules, a signaling complex is assembled. Toll binds Myd88 through TIR domains (circles), and in turn Myd88 binds Tube and Pelle through their death domains (triangles). The kinase Pelle gets activated by autophosphorylation and then phosphorylates cactus (an IкB inhibitor), marking it for degradation. The NF- $\mathrm{B}$ transcription factors Dorsal or Dif get free and translocate to the nucleus, where they activate transcription of antimicrobial peptides (AMP). P represents a phosphate group. 


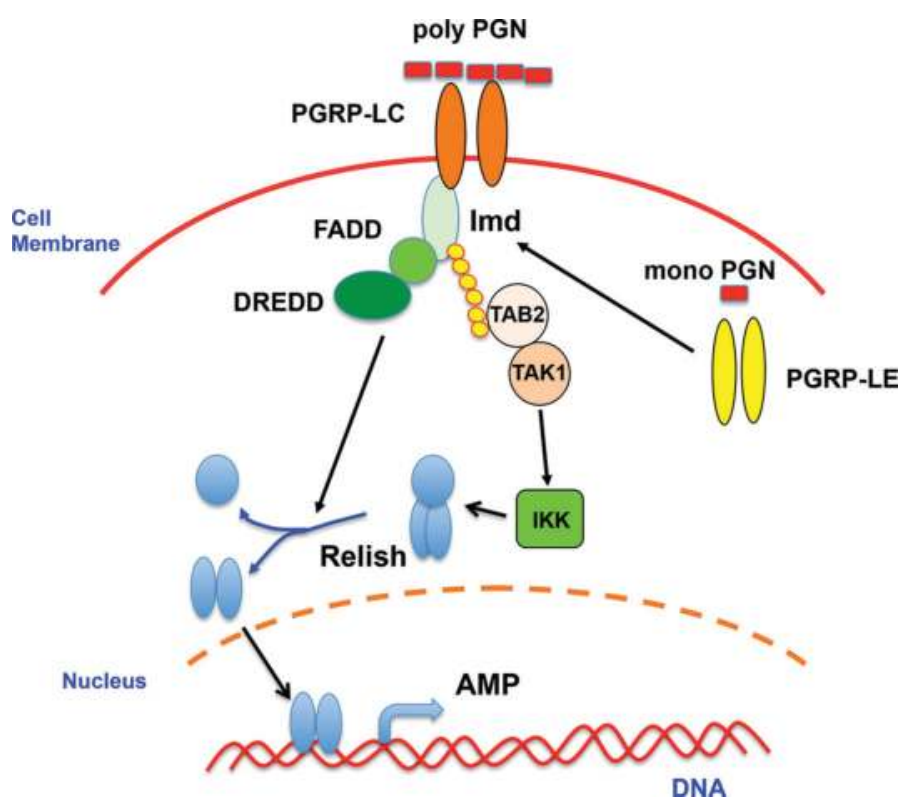

Figure 3. The Imd signaling pathway. In the case of Gram-negative bacteria and some Gram-positive species, polymeric DAP-type peptidoglycan (poly PGN) is recognized by a dimer of PGRP-LC to activate Imd signaling. Imd binds to FADD (Fas-associated protein with death domain), and then the caspase DREDD (FADD-death-related ced-3/Nedd2like protein) is recruited. DREDD cleaves Imd, which is then activated by K63-ubiquitination. The K63-polyubiquitin chains (yellow circles) help connect to TAB2 (TAK1-associated binding protein 2) and to recruit and activate TAK1 (transforming growth factor beta (TGF- $\beta$ )-activated kinase 1). TAK1 is then responsible for activating the IKK complex, which phosphorylates the NF-kB-like nuclear factor Relish. DREDD is also required for mediating the cleavage of the precursor Relish. Upon cleavage and phosphorylation, free Relish can translocate into the nucleus, where it activates transcription of specific antimicrobial peptides (AMP). Monomeric peptidoglycan can be recognized intracellularly by the receptor PGRP-LE, and also activate the Imd pathway.

\subsubsection{The JAK-STAT pathway}

As mentioned above, the Toll and Imd pathways were first described in Drosophila and then similar pathways were found in mammals, due to the fact that the central components of these pathways are conserved in evolution. In contrast, the Janus kinase-signal transducer and activator of transcription (JAK-STAT) signaling pathway was first recognized as important in regulating multiple processes of human immunity [77], including control of inflammation and activation of leukocytes, such as neutrophils and macrophages. Now, research is looking back to the fruit fly as a useful model system for elucidating the in vivo roles of the JAK-STAT pathway and its regulators, which are challenging to demonstrate in mammalian systems [55].

The canonical signaling model for the JAK-STAT pathway indicates that after binding of a cytokine to its receptor, the receptor dimerizes and JAKs that are constitutively associated with the cytoplasmic tail of the receptor get activated. Activated JAKs phosphorylate each other and specific tyrosine residues on the cytoplasmic part of the receptor. These phosphorylated tyrosines become docking sites for the Src homology $2(\mathrm{SH} 2)$ domains of STAT molecules. The STATs are then tyrosine phosphorylated by JAKs, which allows them to form dimers and translocate into 
the nucleus, where they bind the promoters of their target genes [78]. In humans, this pathway is very complex due to the number of cytokines that can activate it, and the ability of the JAKs and STATs to form homo- and heterodimers and associate with multiple transcription factors and coactivators. There are four JAKs (JAK1, JAK2, JAK3, and TYK2) and seven STATs (STAT1, STAT2, STAT3, STAT4, STAT5A, STAT5B, and STAT6) [78]. In Drosophila, the known JAK-STAT pathway ligands consist of only three cytokine-like proteins called unpaired (upd), upd2, and upd3 [79]. All three upd molecule signal via a single receptor, Domeless (Dome) [80], which binds to a single JAK, hopscotch (hop) [81], and one STAT transcription factor, Stat92E [82] (Figure 4). In addition, in mammals, the JAK-STAT pathway is regulated at the receptor level by the membrane-spanning signal transducer protein gp130 [83], and by negative feedback loops involving the suppressor of cytokine signaling (SOCS) proteins [84]. In Drosophila, similar regulating mechanisms have been found. Eye transformer (ET), a no signaling protein that resembles gp130, is associated with the receptor complex, interacting with both Dome and hop. Thus, ET seems to inhibit intracellular signaling [85, 86] (Figure 4). Also, three members of the SOCS family are found in Drosophila, Socs16D, Socs36E, and Socs44A. Of these, Socs36E is the principal negative feedback loop regulator, and it is strongly induced by JAK-STAT signaling [87] (Figure 4).

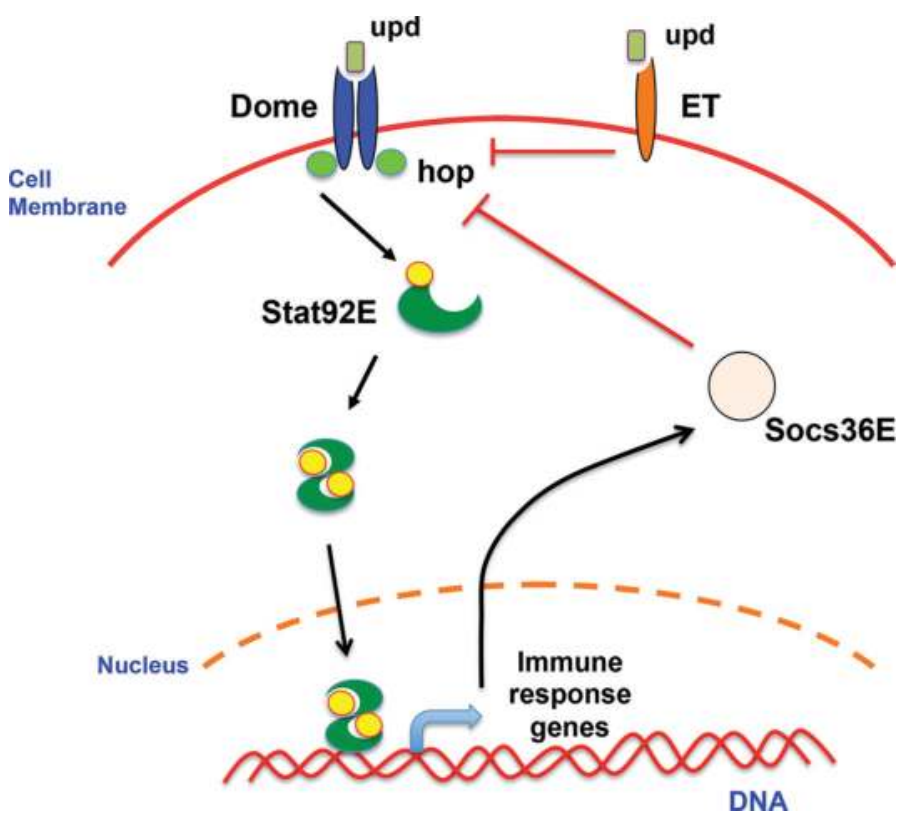

Figure 4. The JAK-STAT signaling pathway. Three cytokine-like proteins called unpaired (upd), upd2, and upd3 signal via the receptor Domeless (Dome), which binds to a single JAK, hopscotch (hop). Upon receptor activation, hopscotch phosphorylates itself and specific tyrosine residues on the cytoplasmic part of the receptor. These phosphorylated tyrosines become docking sites for the STAT transcription factor, Stat92E. Hopscotch also phosphorylates Stat92E at tyrosine residues, allowing it to form dimers and then translocate into the nucleus, where it binds the promoters of their target genes. This pathway is also regulated by a negative feedback loop involving the suppressor of cytokine signaling (SOCS) protein Socs36E, which is upregulated by STAT-JAK signaling. In addition, eye transformer (ET), a nonsignaling receptor for upd, is able to associate with the receptor complex, interacting with both Dome and hop. Thus, ET seems to inhibit intracellular signaling. 
As described above, the humoral immune response in Drosophila is mainly controlled by the Toll and Imd pathways in cells of the fat-body and leads to the production of antimicrobial peptides [51,54]. Also, the JAK-STAT pathway leads to production by the fat-body of other proteins, including cytokines and stress response proteins. This pathway is activated by the ligand upd3. Various stress conditions, such as injury, heat-shock, or dehydration, induce hemocytes to secrete upd3 [88] (Figure 5). Moreover, the JAK-STAT pathway has been shown to contribute to the Drosophila viral response. Established JAK-STAT pathway target genes, such as TotM, upd2, and upd3, are all induced by multiple viruses [89]. Finally, the JAK-STAT pathway also contributes to the antimicrobial defense in the gut by inducing the expression of a subset of antimicrobial peptides, such as drosomycin-like peptide (dro3). However, this response seems to be mediated by recognition of cell damage rather than the pathogen [90] (Figure 5).

A
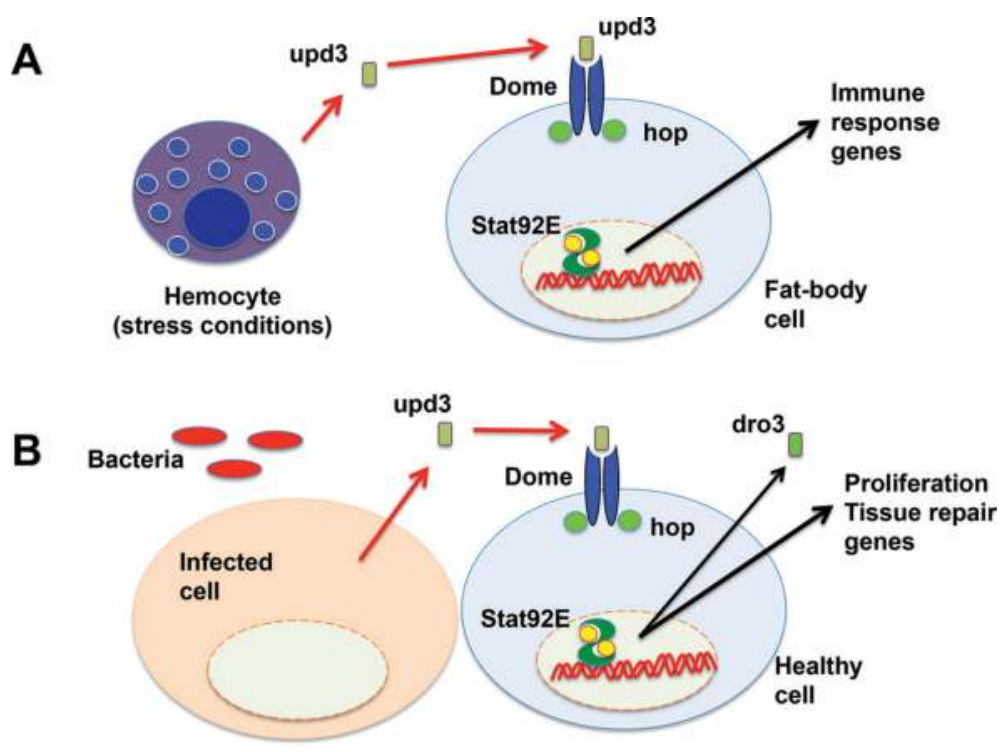

Figure 5. Activation signals for the JAK-STAT signaling pathway. (A) In Drosophila, hemocytes participate in recognizing stress conditions by secreting the cytokine-like protein upd3, which binds to the receptor Domeless (Dome). This activates the JAK, hopscotch (hop) and the STAT, Stat92E for induction of immune response genes. (B) In the fly gut epithelium, an infected (with pathogenic bacteria, for example) cell also produces upd3 for activating the JAK-STAT pathway in neighbor cells. These cells then produce antimicrobial peptides, such as drosomycin-like peptide (dro3). Also some proliferation and tissue repair responses are activated to protect the epithelium from infection.

\section{Receptors sensing infections}

Innate immune responses of insects can be triggered through the interaction of hemocyte receptors or plasma proteins with specific molecules, such as lipids or sugars, on the surface of many microorganisms [91]. Pattern-recognition proteins can be grouped into various types including peptidoglycan recognition protein (PGRP) [92], $\beta$-1,3-glucan recognition protein $(\beta G R P)$, hemolin, and C-type lectins. 


\subsection{Peptidoglycan recognition proteins (PGRPs)}

Peptidoglycan recognition proteins (PGRPs) are innate immunity proteins, conserved from insects to mammals, which recognize bacterial peptidoglycan, and function in antibacterial immunity and inflammation. Mammals have four PGRPs [93, 94]. They are secreted proteins expressed in polymorphonuclear leukocytes (PGRP1), in liver (PGRP2), or in secretions (PGRP3 and PGRP4). All PGRPs recognize bacterial peptidoglycan and three of them (PGRP1, PGRP3, and PGRP4) are directly bactericidal for both Gram-positive and Gramnegative bacteria [94]. Insects have up to 19 PGRPs, classified into short (S) and long (L) forms. The short forms are present in the hemolymph, cuticle, and fat-body cells, whereas the long forms are mainly expressed in hemocytes $[95,96]$. The expression of insect PGRPs is often upregulated by exposure to bacteria. These receptors activate the Toll or the Imd signal transduction pathways (described above) or induce proteolytic cascades that generate antimicrobial products [94, 97].

Known functions of PGRPs in Drosophila are as follows: the PGRP-SA in hemolymph binds to Lys-type peptidoglycan and together with PGRP-SD and Gram-negative binding protein (GNBP) 1 leads to activation of the Toll pathway (Figure 1). GNBP3 also leads to activation of the Toll pathway in response to yeast. These pattern-recognition proteins initiate the serine protease cascades that lead to activation of the Spätzle-processing enzyme (SPE), which in turn cleaves proSpätzle to generate free Spätzle, the ligand for Toll (Figure 1). Similarly, the Imd pathway is activated when the PGRP-LCx homodimer complex binds DAP-type polymeric peptidoglycan, or the heterodimer PGRP-LCx/ PGRP-LCa binds DAP-type monomeric peptidoglycan. PGRP-LE can bind both polymeric and monomeric DAP-type peptidoglycan. Extracellular PGRP-LE activates the Imd pathway through PGRP-LC transmembrane receptors and is also involved in activation of the prophenoloxidase (proPO) cascade upstream of the proPO-activating enzyme (PPAE) (Figure 6). Intracellular PGRP-LE can also activate the Imd pathway by recognizing intracellular bacteria with DAP-type peptidoglycan and binding to the Imd adaptor protein. In addition, intracellular PGRP-LE can activate autophagy in an Imd pathway-independent manner (Figure 6). PGRP-LF functions as an inhibitor of the Imd pathway, because it can bind to PGRP-LCx but not to peptidoglycan. In this manner, it prevents the formation of a PGRP-LC active dimer. PGRP-LB and -SC1a/1b/2 cleave DAP-type peptidoglycan to inactive fragments, thus preventing activation of the Imd pathway. In addition to its scavenger function, PGRP-SC1a is involved in the phagocytosis of bacteria as an opsonin. PGRP-SB1 is directly bactericidal due to its DAP-type peptidoglycan-specific amidase activity [98] (Figure 6).

\subsection{Beta-1,3-glucan recognition proteins ( $\beta$ GRPs)}

Insect $\beta$-1,3-glucan recognition proteins ( $\beta$ GRPs) and Gram-negative bacteria binding proteins (GNBPs) are a family of plasma proteins with an amino-terminal glucan-binding domain and a carboxyl-terminal region similar to $\beta$-1,3-glucanases [99]. All $\beta \beta$ GRPs bind to $\beta$-1,3-glucans on bacteria and can activate the proPO cascade. Manduca sexta $\beta$ GRP1 is constitutively expressed in fat-body, whereas $\beta$ GRP2 gene expression is increased during the early wandering stage 
prior to pupation or after and immune challenge $[5,100]$. Binding of these $\beta$ GRPs to hemolymph proteinase-14 precursor (proHP14) induces autoactivation of HP14 to initiate a proteinase cascade leading to proPO activation [101]. A $\beta$ GRP with glucanase activity was isolated from midgut extract of Helicoverpa armigera larvae. This enzyme hydrolyzes $\beta$-1,3-glucan but not $\beta$-1,4-glucan, and it probably functions more as a digestive enzyme than an immune activator [102].

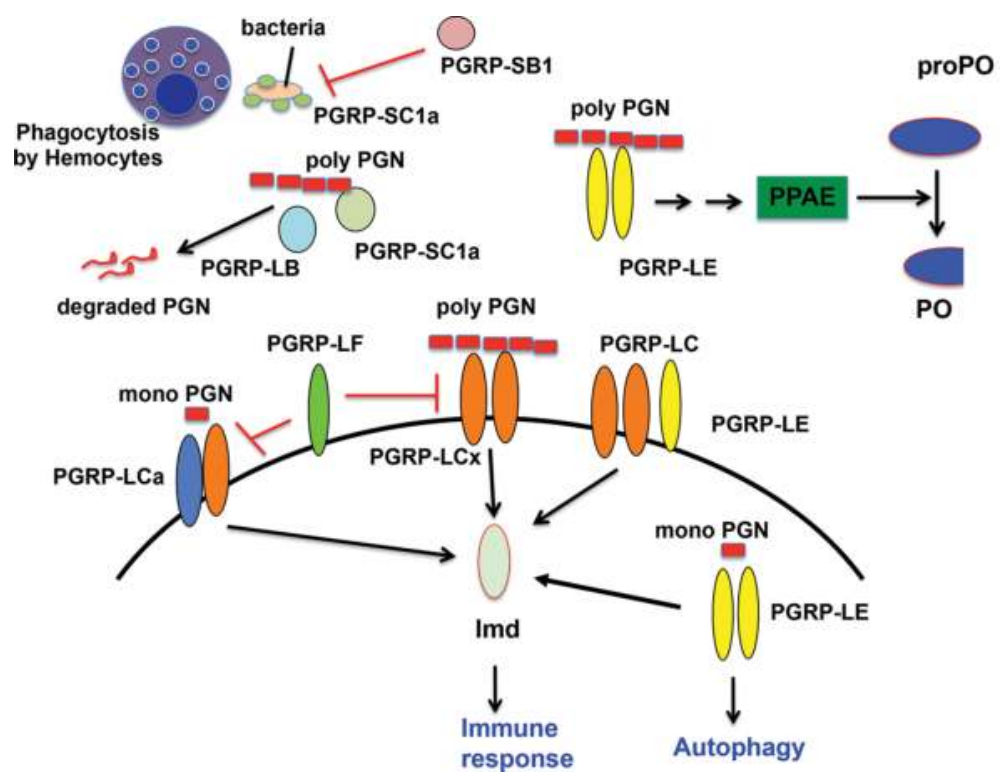

Figure 6. Known functions of PGRPs in Drosophila. Peptidoglycan recognition proteins (PGRPs) are innate immunity proteins, conserved from insects to mammals, which recognize bacterial peptidoglycan. The Imd pathway is activated when the PGRP-LCx homodimer complex binds polymeric peptidoglycan (poly PGN), or the heterodimer PGRP-LCx/PGRP-LCa binds monomeric peptidoglycan (mono PGN). PGRP-LE can bind both polymeric and monomeric peptidoglycan. Extracellular PGRP-LE activates the Imd pathway through PGRP-LC transmembrane receptors and is also involved in activation of the prophenoloxidase (proPO) cascade upstream of the proPO-activating enzyme (PPAE). Intracellular PGRP-LE can also activate the Imd pathway by recognizing intracellular monomeric peptidoglycan and inducing Imd signaling or autophagy independently of Imd. PGRP-LF functions as an inhibitor of the Imd pathway. PGRP-LB and -SC1a/1b/2 cleave DAP-type peptidoglycan to inactive fragments, thus preventing activation of the Imd pathway. In addition, PGRP-SC1a acts as an opsonin for phagocytosis of bacteria. PGRP-SB1 is directly bactericidal due to its DAP-type peptidoglycan-specific amidase activity.

\subsection{Hemolin}

Hemolin is a plasma protein with four immunoglobulin (Ig) domains commonly found in adhesion molecules of vertebrates [103]. Hemolin is a common protein in several Lepidopteran species, including B. mori [32], Antheraea mylitta [104], Plutella xylostella [105], and Samia cynthia [106], but it has not been identified in insects from other orders. Hemolin binds to bacterial LPS and lipoteichoic acid [23]. Hemolin also associates with hemocytes, thus serving as a bridge between microorganisms and hemocytes, and inducing phagocytosis or nodulation [107]. 


\subsection{C-type lectins (CTLs)}

C-type lectins (CTLs) from animals are a large group of carbohydrate-recognition molecules that bind ligands in a calcium-dependent manner. Several C-type lectins have been found in Lepidoptera including LPS-binding protein (LBP or CTL20), immulectins -1, -2, -3, and -4, [108, 109], CTL10 [110], CTL11, CTL19, and CTL21 [32]. All these lectins have two carbohydrate-recognition domains, and their genes suggest that these types of lectins are rather unique to Lepidoptera, since they have not been found in other insect species [5].

Most Lepidopteran CTLs bind to bacterial LPS and some also to lipoteichoic acid [108, 109, $111]$, inducing agglutination of bacteria and yeast [109, 110], probably because each of the two carbohydrate-binding domains bind to sugar residues on the surface of adjacent microbial cells [5]. This microbial aggregation may help hemocytes eliminate pathogens via phagocytosis and nodule formation.

\section{The cellular response}

Cellular immune responses are immediately after an invasion of the hemocele, while humoral responses appear several hours after an infection. Hemocytes are responsible for a variety of defense responses in insects. Many variations in hemocyte immune responses exist due to the presence of millions of insect species, and we are just beginning to understand these variations [7, 112]. However, a number of frequent cellular immune responses have been described in most insects studied. These responses include nodulation, encapsulation, melanization, and phagocytosis.

\subsection{Hemocytes}

There are various types of hemocytes described in insects, including granular cells, crystal cells, oenocytoids, and plasmatocytes [8]. These hemocytes are capable of adhesion and phagocytosis [2]. Other types of hemocytes like oenocytoids can produce proPO. This classification of hemocytes, based on morphology, does not always correlate well with cell function. Thus, other attempts have been made to classify hemocyte types. By flow cytometry, three major types of hemocytes can be separated: large granular cells, small semigranular cells, and small hyaline cells [113]. Also, there are some monoclonal antibodies that can distinguish hemocytes based on antigenicity rather than morphology [114, 115]. A number of those monoclonal antibodies could also inhibit some cellular responses [116, 117]. In D. melanogaster, three types of hemocytes have been described in greater detail: crystal cells, plasmatocytes, and lamellocytes [118].

Crystal cells are relatively large cells with crystalline inclusions, thus their name. They produce the zymogen proPO, which is activated during melanization. Melanin deposits are important for wound healing or encapsulation of parasites [119, 120]. Plasmatocytes comprise approximately $95 \%$ of the hemocyte pool. They are rather small cells (around 10 $\mu \mathrm{m}$ in diameter), but extend large lamellipodial protrusions and form dynamic filopodia $[121,122]$. Plasmatocytes are long-lived cells that seem to persist through the entire life 
of a fly [122]. Mature plasmatocytes express Croquemort (Crq), a CD36 scavenger receptor ortholog, Peroxidasin, an extracellular matrix enzyme, and phagocytic receptors [123]. Lamellocytes are flat cells that appear during larval stages and only detectable when the larvae is infected by parasitic organisms. These hemocytes are mainly responsible for encapsulating the parasitoid wasp egg [119]. Lamellocytes seem to differentiate from a precursor pool of plasmatocytes [124], during a wasp egg infestation and also during sterile injury $[125,126]$ (Figure 7).

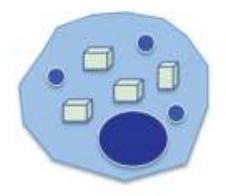

Crystal cell

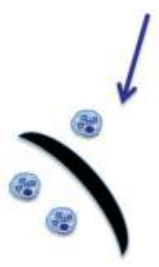

Melanization

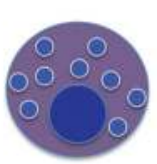

Plasmatocyte

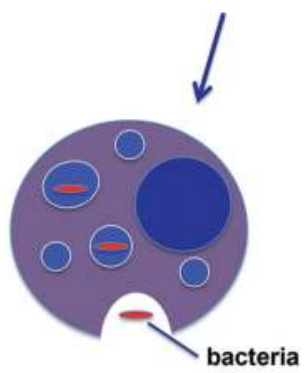

Phagocytosis

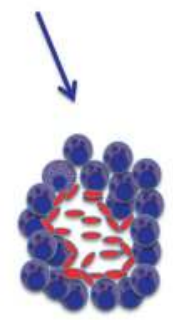

Nodulation

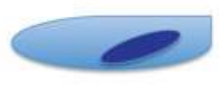

Lamellocyte

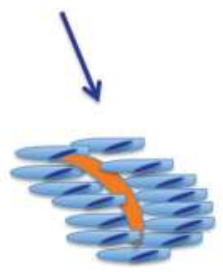

Encapsulation

Figure 7. Types and functions of hemocytes in Drosophila. Crystal cells are relatively large cells with crystalline inclusions. They produce the zymogen prophenoloxidase, which is activated during melanization. Plasmatocytes are granular cells that comprise approximately $90 \%$ of all hemocytes. They express phagocytic receptors and eliminate most of the invading bacteria by phagocytosis or nodulation. Lamellocytes are flat cells that appear during larval stages and only detectable when the larvae are infected by parasitic organisms. These hemocytes are mainly responsible for encapsulating the parasitoid wasp egg. Images are not drawn to scale.

Independently of the type of hemocyte involved, insect immune responses initiate with adhesion of granular hemocytes and plasmatocytes to foreign surfaces or to other cells [127, 128]. Adhesion of hemocytes leads to phagocytosis and also to nodule formation and encapsulation. These cellular innate functions are described next.

\subsection{Phagocytosis}

Phagocytosis is the process by which cells recognize, bind, and ingest relatively large particles [19]. In insects, phagocytosis is performed by a subset of hemocytes in the hemolymph [7]. Professional phagocytes in Diptera and Lepidoptera have been described as plasmatocytes and granular hemocytes, respectively [129]. In agreement with this, plasmatocytes or granulocytes are the main phagocytic cells in most insects [7, 113, 130, 131]. Recognition of target particles for phagocytosis can be direct by specific cell-surface receptors, or indirect 
by opsonins that cover the particle so that it can be detected by phagocytic receptors. During development, phagocytic hemocytes eliminate many dying cells, which are detected by the scavenger receptors Croquemort [132], and Draper [133]. In the embryo, hemocytes phagocyte live bacteria but the receptors involved have not been yet identified [134]. In the larva and adult insects, recognition of microorganisms is mediated by the Nimrod family receptors Eater [135] and NimC1 [136], which bind to both Gram-positive and Gram-negative bacteria. Cytokines capable of activating hemocyte functions have also been reported in Lepidoptera insects. A hemocyte chemotactic peptide from Pseudaletia separata induces migration and aggregation of hemocytes [137]. This peptide belongs to a group of Lepidopteran cytokines called ENF peptides, which have various biological activities, including plasmatocyte adhesion and spreading, and release of proPO activation [138].

\subsection{Nodulation}

When the initial phagocytic immune response is not sufficient, hemocytes activate other mechanisms to control infections. To deal with large bacterial loads, hemocytes form nodules to control the infections. Nodulation involves the formation of multicellular hemocyte aggregates that entrap large numbers of bacteria. First, hemocytes surround bacteria and then join other hemocytes to form small aggregates. These cell aggregates continue growing by adding more hemocytes until large nodules are formed. At the end, the nodule is covered with layers of flattened hemocytes and it is melanized. Melanin-covered nodules efficiently isolate bacteria from the hemolymph. Although the process of nodule formation is not completely characterized, certain molecules such as eicosanoids, proPO, and dopa decarboxylase (Ddc) are important for nodule formation in many insect species [139-142]. In addition, screenings for novel immune genes from an Indian saturniid silkmoth (A. mylitta) larvae, and from B. mori larvae, identified two proteins, Noduler [143] and Reeler1 [144], respectively, as essential molecules in mediating nodulation against $E$. coli $\mathrm{K} 12$ and B. subtilis bacteria challenge.

\subsection{Encapsulation}

For larger pathogens such as parasites, protozoa, and nematodes, hemocytes respond by forming a capsule around the foreign organism. Lamellocytes are the effector cells of encapsulation. Lamellocytes bind to the target in multiple cell layers until they form a capsule around the invader. The capsule is normally melanized at the end by degranulation of crystal cells [145]. Inside the capsule the invading organism is killed by reactive cytotoxic products or by asphyxia [146]. Insect hemocytes aggregate in multiple layers during encapsulation and bind to microorganisms during phagocytosis. These functions can be mediated by integrins [147] and indeed various integrins have been found in insect hemocytes [129]. Integrins are also relevant for encapsulation. Various $\alpha$ and $\beta$ integrins are required for microbial recognition by $M$. sexta hemocytes [148], and in Drosophila, the $\beta 2$-integrin myospheroid is required for attachment to the wasp egg [149].

Interestingly, recent reports have shown that insect hemocytes can release chromatin in a controlled manner to form extracellular traps [150], similar to the NETs formed by mammalian 
neutrophils [151, 152]. Hemocytes release their nucleic acids in a process known as ETosis. The chromatin fibers participate in histone-mediated killing of microorganisms [150], and also in the process of encapsulation by creating a scaffold on which hemocytes can assemble [153].

\subsection{Melanization}

Melanization is the process of melanin formation. It is activated during wound healing and also in nodule and capsule formation against large pathogens or parasites in several insects [8, 154]. The enzyme phenoloxidase (PO) is a key in this process. Activation of proPO to PO [155] is mediated by a Serine proteinase cascade [156] and requires pattern-recognition proteins such as PGRP or $\beta$ GRP. Then active PO binds to foreign surfaces including hemocyte membranes [157], where it initiates melanin formation. PO acts on tyrosine and converts it to dopa [22]. Dopa can then be decarboxylated by Ddc to dopamine or further oxidized by PO to dopaquinone. Both products are then further metabolized to eumelanin and finally melanin [22].

\section{Antivirus insect response}

Insects, like any other organism, are also infected by viruses. Some viruses are restricted to insect cells and are pathogenic to them; other viruses are transmitted to mammals by biting insects. Understanding the insect innate immune response against viruses thus has tremendous medical and economic importance.

The major mechanism of antiviral defense is the RNA interference (RNAi) pathway that recognizes virus-derived double-stranded RNA (dsRNA) to produce small, interfering RNAs (siRNAs). These siRNAs, in turn, target viral RNA for degradation and hence suppress virus replication. In addition, other innate antimicrobial pathways such as Imd, Toll, and JAK-STAT pathways have also been shown to play important roles in insect antiviral responses. In particular, the JAK-STAT pathway seems to function similarly to the mammalian interferon system. A virus-infected cell sends a signal that activates this pathway in uninfected bystander cells leading to antiviral activity. Finally, the autophagy pathway has also been suggested to be important in some viral infections.

\subsection{The RNA interference (RNAi) pathway}

When challenged with viruses, the most robust insect response is through the RNA interference (RNAi) pathway (Figure 8). Double-stranded viral RNA is detected by Dicer-2 (a member of the RNase III family of endoribonucleases) together with the protein R2D2 [158, 159]. Then, Dicer-2 cleaves the dsRNA into small (21-nucleotide) duplex DNA fragments [160, 161]. Unwinding of the duplex takes place and a guide strand is selected on the basis of complementarity. The siRNA guide strand is then loaded into the RNA-induced silencing complex (RISC), which includes the RNase Argonaute [162]. A target viral RNA pairs with the guide strand, and it is degraded by Argonaut (Figure 8).

The importance of the RNAi pathway for controlling virus infections is highlighted by the fact that several viruses have been found to produce RNAi suppressor proteins (1A proteins 
in Nodaviridae, or B2 proteins in Dicistroviridae) that block the action of the RISC during infection [163, 164]. The B2 protein from the flock house virus (FHV) is a dimer that binds to dsRNA and prevents the cleavage of dsRNA by Dicer-2 [165]. The A1 protein from Drosophila $\mathrm{C}$ virus (DCV) functions similarly to FHV B2, by binding to dsRNA and preventing cleavage [164]. In contrast, the 1A protein of cricket paralysis virus (CrPV) interacts with Argonaute and inhibits its RNAse activity [164] (Figure 8). When viruses do not have these proteins they replicate poorly and the insect is able to clear the infection completely. The RNAi pathway is clearly very important also for protecting mammalian cells against viruses. Recently, the NS4B protein of dengue virus 2 (DENV-2), flavivirus was found to inhibit the siRNA pathways both in mammalian and insect (Sf21) cells [166].

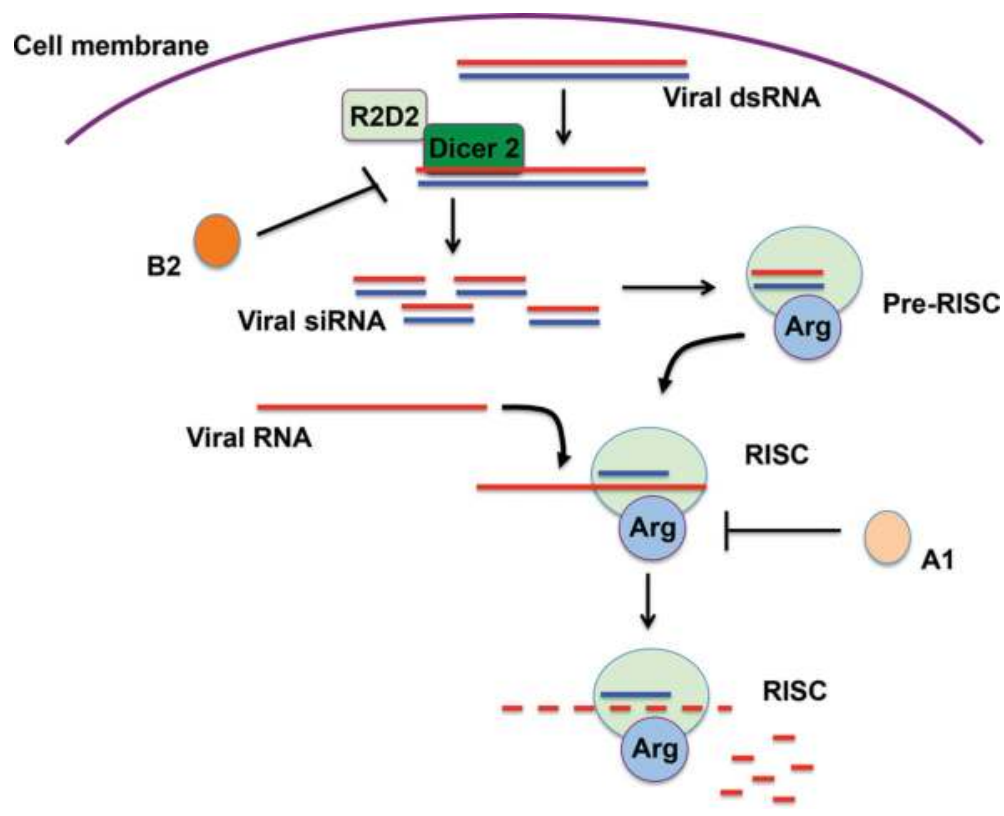

Figure 8. RNA interference (RNAi) pathway. Double-stranded viral RNA is detected by Dicer-2 together with the protein R2D2. Then, Dicer-2 cleaves the dsRNA into small duplex DNA fragments. These siRNA fragments are loaded into the preRNA-induced silencing complex (preRISC), which includes the RNase Argonaute (Arg). A target viral RNA pairs with the guide strand and Argonaut degrades it. RNAi suppressor proteins from some viruses can block the RNAi pathway. The B2 protein from the flock house virus (FHV) prevents the cleavage of dsRNA by Dicer-2; the 1A protein of cricket paralysis virus (CrPV) interacts with Argonaute and inhibits its RNAse activity.

\subsection{The JAK-STAT pathway}

In addition to the RNAi pathway, the Toll $[167,168]$ and Imd signaling $[169,170]$ pathways have been also reported to be involved in antivirus responses. In addition to AMPs, these pathways induce particular sets of genes that are distinct from the genes induced by bacteria or fungi, depending on the virus involved [171]. The actual mechanism for virus recognition and the particular response induced through these pathways is just beginning to be eluci- 
dated. In contrast, the JAK-STAT pathway response to viruses seems to be more relevant for preventing the spread of infection [172]. Recent reports also suggest that the JAK-STAT pathway may function similarly to the mammalian interferon system [173]. Infected cells produce factors that activate this pathway in uninfected bystander cells inducing an antiviral state in those cells $[172,173]$.

As mentioned earlier, the JAK-STAT pathway was initially characterized for its role in development and hemocyte proliferation [77]. The JAK-STAT pathway also gets activated in respond to bacterial infections leading to production of AMPs and other effector molecules [55, 174]. This pathway is activated in a paracrine fashion through the binding of secreted ligands. In the case of virus infections, a novel ligand for the JAK-STAT pathway has recently been identified. In fruit flies, DCV and Sindbis virus (SINV) infections result in increased expression of mRNA for Vago, an $18 \mathrm{kDa}$ cysteine-rich protein with a single von Willebrand factor type C motif [175]. Vago was then shown to be secreted by West Nile virus (WNV)-infected Culex quinquefasciatus (southern house mosquito) cells [173]. In addition, Vago mRNA expression was dependent on Dicer-2 but no other RNAi pathway components [173]. Secreted Vago then goes and activates the JAK-STAT pathway in other cells, but interestingly it does not bind the Dome receptor. A different unknown receptor must be responsible for activation of this signaling pathway (Figure 9). This creates a new level of complexity to our understanding of the JAK-STAT pathway in insects [176]. The mechanism by which the JAK-STAT pathway creates an antiviral state in the cells is also not known. Future research will help understanding this complex immune response in insects.

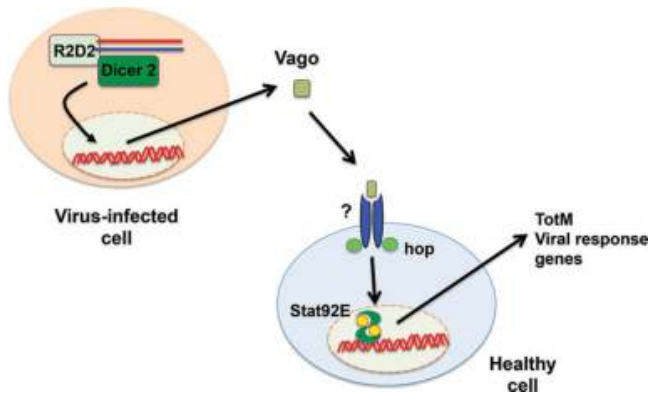

Figure 9. RNA interference (RNAi) pathway and JAK-STAT pathway in viral infections. In a virus-infected cell, an increased expression of mRNA for Vago is observed. The Vago mRNA expression is dependent on Dicer-2. Secreted Vago then goes and activates the JAK-STAT pathway in other cells, but interestingly it does not bind the Dome receptor. A different unknown receptor (?) must be responsible for activation of this signaling pathway to induce expression of viral response genes, including TotM, upd2, and upd3.

\subsection{The autophagy pathway}

Autophagy has also been proposed as another antiviral mechanism in insects that is independent of the Toll, Imd, or JAK-STAT pathways $[177,178]$. Autophagy is the process by which doublemembrane vesicles named autophagosomes are formed inside cells. These vesicles are formed with newly synthesized membranes that incorporate large cytoplasmic components including damaged organelles or protein aggregates. Then, the autophagosome fuses with lysosomes and degrades its content. Autophagy is induced by several stress signals including nutrient 
starvation, infection, and cellular repair mechanisms. In this manner, the degradative process of autophagy helps recycle nutrients and maintains cellular homeostasis [179]. The signaling pathway to autophagy involves the phosphoinositide 3-kinase (PI3K)-Akt pathway, which augments the level of TOR, a negative regulator of autophagy [180] (Figure 10). During growing conditions, TOR is active and phosphorylates Autophagy-related (Atg) 13 protein at multiple sites. This prevents Atg13 to bind with Atg1, a central regulator for autophagy [180], leading to decreased Atg1 kinase activity and blocking autophagy (Figure 10). During starvation conditions, TOR activity is reduced and Atg13 is rapidly dephosphorylated and forms a complex with Atg1, thus activating it. Atg1 in turn binds to other Atg proteins for assembly of the preautophagosomal structure (PAS) leading to autophagy (Figure 10). Different Atg proteins accumulate at the PAS under normal growing conditions to generate cytoplasm to vacuole targeting (Cvt) vesicles, or under starvation conditions to generate autophagosomes [181].

In an infection of Drosophila with vesicular stomatitis virus (VSV), the PI3K-Akt-TOR signaling pathway is inhibited. This activates autophagy and in turn decreases viral replication [178]. The viral surface glycoprotein, VSV-G, was proposed to be the pathogen-associated molecular pattern (PAMP) that initiated this cell response [178]. More recently, it was found that, the Drosophila TLR ortholog, Toll-7, was responsible for sensing VSV on the cell surface (Figure 10). Toll-7 signaling was activated upon VSV infection and knockdown of Toll-7 resulted in a higher viral protein level in vitro and greater pathogenesis in vivo [177].

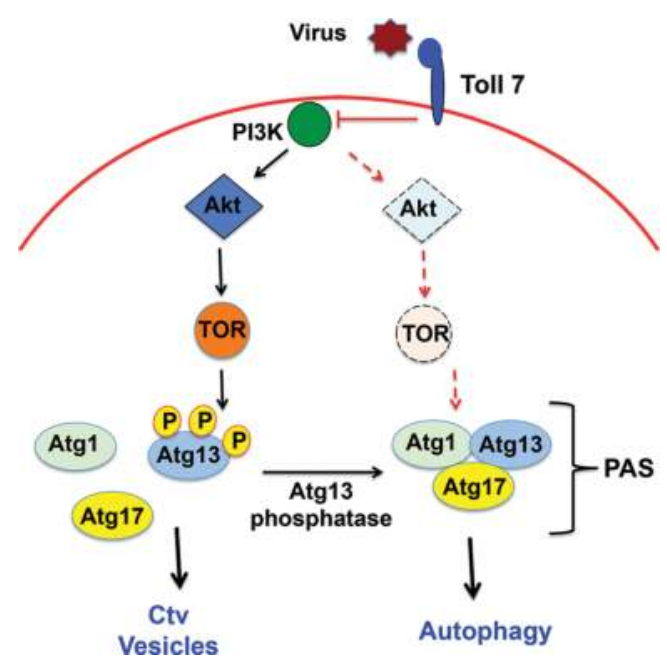

Figure 10. Autophagy response in viral infections. The signaling pathway to autophagy involves the phosphoinositide 3-kinase (PI3K)-Akt pathway, leading to activation of TOR. This kinase phosphorylates autophagy-related (Atg) 13 protein at multiple sites. This prevents Atg13 binding to Atg1 and other Atg proteins like Atg17, for assembly of the preautophagosomal structure (PAS), which leads to autophagy. Different Atg proteins accumulate with Atg1 under normal growing conditions to generate cytoplasm to vacuole targeting (Cvt) vesicles. During an infection with vesicular stomatitis virus (VSV), the receptor Toll-7 detects the virus, and the PI3K-Akt-TOR signaling pathway is inhibited. This activates autophagy and in turn decreases viral replication. 


\section{Conclusion}

Insects clearly possess powerful defense mechanisms for fighting infections. Cellular responses involve phagocytosis of bacteria, and encapsulation of parasites, while humoral responses involve secretion of antimicrobial peptides into the hemolymph. Recognition of foreign pathogens involves specific receptors such as peptidoglycan recognition proteins (PGRPs), $\beta$-glucan recognition proteins ( $\beta$ GRPs), and Toll-related proteins. These receptors activate signaling pathways such as the Toll, the Imd, and the JAK-STAT pathways. The particular pathway activated by each pathogen and the final outcome in each case are still not completely known. This is particularly true for viral infections. Thus, future research in the area of insect immunity promises to be full of surprises.

Another fascinating aspect of insect defense mechanisms against infections is the current view that insects depend only on its innate immune response to fight invading microorganisms. By definition, innate immunity lacks adaptive characteristics. However, there are some reports showing that in Drosophila, an initial sublethal exposure to Streptococcus pneumoniae can protect flies from a second lethal exposure to the same bacteria [182]. Although not all microbial challenges generate this specific primed response, the fungus Beauveria bassiana, a natural fly pathogen, can also induce specific protection against a second exposure to the fungus [182]. These results indicate that insect immune responses can indeed adapt and suggest that insect hemocytes may also present an activation response similar to the one known in mammalian leukocytes.

Finally, most of what we know about insect innate immunity comes from studies of Drosophila, where genetics analysis has been instrumental in elucidating the antimicrobial peptide response, as well as to open the door for the study of Toll-like receptors, which are essential for the innate immune response of mammals. Similarly, future genetic screens will help identifying novel host antiviral genes and also the receptor molecules that sense viral infection. Yet, it is important to keep in mind that insect-pathogen interactions have coevolved. Thus, it is important to confirm findings from Drosophila studies in other insect species $[8,128,176]$.

\section{Acknowledgements}

This work was supported by grant 254434 from Consejo Nacional de Ciencia y Tecnología, Mexico.

\section{Author details}

Carlos Rosales

Address all correspondence to: carosal@unam.mx

Immunology Department, Instituto de Investigaciones Biomédicas, Universidad Nacional Autónoma de México, Mexico City, Mexico 


\section{References}

[1] Kanost MR, Jiang H, Yu XQ: Innate immune responses of a lepidopteran insect, Manduca sexta. Immunol. Rev. 2004; 198:97-105.

[2] Lavine MD, Strand MR: Insect hemocytes and their role in immunity. Insect Biochem. Mol. Biol. 2002; 32:1295-1309.

[3] Ashida M, Brey PT: Role of the integument in insect defense: pro-phenol oxidase cascade in the cuticular matrix. Proc. Natl. Acad. Sci. U S A 1995; 92:10698-10702.

[4] Hegedus D, Erlandson M, Gillott C, Toprak U: New insights into peritrophic matrix synthesis, architecture, and function. Annu. Rev. Entomol. 2009; 54:285-302. doi: 10.1146/ annurev.ento.54.110807.090559

[5] Jiang H, Vilcinskas A, Kanost MR: Immunity in lepidopteran insects. Adv. Exp. Med. Biol. 2010; 708:181-204.

[6] Tsakas S, Marmaras VJ: Insect immunity and its signalling: an overview. Invertebrate Surv. J. 2010; 7:228-238.

[7] Browne N, Heelan M, Kavanagh K: An analysis of the structural and functional similarities of insect hemocytes and mammalian phagocytes. Virulence 2013; 4:597-603. doi: 10.4161/viru. 25906

[8] Vlisidou I, Wood W: Drosophila blood cells and their role in immune responses. FEBS J. 2015; 282:1368-1382. doi: 10.1111/febs.13235

[9] Meister M: Blood cells of Drosophila: cell lineages and role in host defence. Curr. Opin. Immunol. 2004; 16:10-15.

[10] Manachini B, Arizza V, Parrinello D, Parrinello N: Hemocytes of Rhynchophorus ferrugineus (Olivier) (Coleoptera: Curculionidae) and their response to Saccharomyces cerevisiae and Bacillus thuringiensis. J. Invertebr. Pathol. 2011; 106:360-365. doi: 10.1016/j.jip.2010.12.006

[11] Wang Q, Liu Y, He HJ, Zhao XF, Wang JX: Immune responses of Helicoverpa armigera to different kinds of pathogens. BMC Immunol. 2010; 11:9. doi: 10.1186/1471-2172-11-9

[12] Williams MJ: Drosophila hemopoiesis and cellular immunity. J. Immunol. 2007; 178:4711-4716.

[13] Defaye A, Evans I, Crozatier M, Wood W, Lemaitre B, Leulier F: Genetic ablation of Drosophila phagocytes reveals their contribution to both development and resistance to bacterial infection. J. Innate Immun. 2009; 1:322-334. doi: 10.1159/000210264

[14] Charroux B, Royet J: Elimination of plasmatocytes by targeted apoptosis reveals their role in multiple aspects of the Drosophila immune response. Proc. Natl. Acad. Sci. U. S. A. 2009; 106:9797-9802. doi: 10.1073/pnas.0903971106

[15] Nehme NT, Quintin J, Cho JH, Lee J, Lafarge MC, Kocks C, Ferrandon D: Relative roles of the cellular and humoral responses in the Drosophila host defense against three Grampositive bacterial infections. PLoS One 2011; 6:e14743. doi: 10.1371/journal.pone.0014743 
[16] Haine ER, Moret Y, Silva-Jothy MT, Rolff J: Antimicrobial defense and persistent infection in insects. Science 2008; 322:1257-1259.

[17] Brivio MF, Mastore M, Nappi AJ: A pathogenic parasite interferes with phagocytosis of insect immunocompetent cells. Dev. Comp. Immunol. 2010; 34:991-998. doi: 10.1016/j. dci.2010.05.002

[18] Kim CH, Shin YP, Noh MY, Jo YH, Han YS, Seong YS, Lee IH: An insect multiligand recognition protein functions as an opsonin for the phagocytosis of microorganisms. J. Biol. Chem. 2010; 285:25243-25250. doi: 10.1074/jbc.M110.134940

[19] Rosales C (ed.): Molecular Mechanisms of Phagocytosis. Georgetown, Texas: Landes Bioscience/Springer Science; 2005.

[20] Cao X, He Y, Hu Y, Wang Y, Chen YR, Bryant B, Clem RJ, Schwartz LM, Blissard G, Jiang H: The immune signaling pathways of Manduca sexta. Insect Biochem. Mol. Biol. 2015; 62:64-74. doi: 10.1016/j.ibmb.2015.03.006

[21] Imler JL, Bulet P: Antimicrobial peptides in Drosophila: structures, activities and gene regulation. Chem. Immunol. Allergy. 2005; 86:1-21.

[22] Marmaras VJ, Lampropoulou M: Regulators and signalling in insect haemocyte immunity. Cell Signal. 2009; 21:186-195.

[23] Yu KH, Kim KN, Lee JH, Lee HS, Kim SH, Cho KY, Nam MH, Lee IH: Comparative study on characteristics of lysozymes from the hemolymph of three lepidopteran larvae, Galleria mellonella, Bombyx mori, Agrius convolvuli. Dev. Comp. Immunol. 2002; 26:707-713.

[24] Chapelle M, Girard PA, Cousserans F, Volkoff NA, Duvic B: Lysozymes and lysozymelike proteins from the fall armyworm, Spodoptera frugiperda. Mol. Immunol. 2009; 47:261269. doi: 10.1016/j.molimm.2009.09.028

[25] Wang WX, Wang YP, Deng XJ, Dang XL, Tian JH, Yi HY, Li YF, He XF, Cao Y, Xia QY et al.: Molecular and functional characterization of a c-type lysozyme from the Asian corn borer, Ostrinia furnacalis. J. Insect Sci. 2009; 9:17. doi: 10.1673/031.009.1701

[26] Vilcinskas A, Matha V: Effect of the entomopathogenic fungus Beauveria bassiana on the humoral immune response of Galleria mellonella larvae (Lepidoptera: Pyralidae). Eur. J. Entomol. 1997; 94:461-472.

[27] Bulet P, Stöcklin R: Insect antimicrobial peptides: structures, properties and gene regulation. Protein Pept. Lett. 2005; 12:3-11.

[28] Lee YS, Yun EK, Jang WS, Kim I, Lee JH, Park SY, Ryu KS, Seo SJ, Kim CH, Lee IH: Purification, cDNA cloning and expression of an insect defensin from the great wax moth, Galleria mellonella. Insect Mol. Biol. 2004; 13:65-72.

[29] Schuhmann B, Seitz V, Vilcinskas A, Podsiadlowski L: Cloning and expression of gallerimycin, an antifungal peptide expressed in immune response of greater wax moth larvae, Galleria mellonella. Arch. Insect Biochem. Physiol. 2003; 53:125-133. 
[30] Volkoff AN, Rocher J, d'Alençon E, Bouton M, Landais I, Quesada-Moraga E, Vey A, Fournier P, Mita K, Devauchelle G: Characterization and transcriptional profiles of three Spodoptera frugiperda genes encoding cysteine-rich peptides. A new class of defensin-like genes from lepidopteran insects? Gene 2003; 319:43-53.

[31] Steiner H, Hultmark D, Engström A, Bennich H, Boman HG: Sequence and specificity of two antibacterial proteins involved in insect immunity. Nature 1981; 292:246-248.

[32] Tanaka H, Ishibashi J, Fujita K, Nakajima Y, Sagisaka A, Tomimoto K, Suzuki N, Yoshiyama M, Kaneko Y, Iwasaki T et al.: A genome-wide analysis of genes and gene families involved in innate immunity of Bombyx mori. Insect Biochem. Mol. Biol. 2008; 38:1087-1110. doi: 10.1016/j.ibmb.2008.09.001

[33] Dai H, Rayaprolu S, Gong Y, Huang R, Prakash O, Jiang H: Solution structure, antibacterial activity, and expression profile of Manduca sexta moricin. J. Pept. Sci. 2008; 14:855863. doi: 10.1002/psc.1016

[34] Brown SE, Howard A, Kasprzak AB, Gordon KH, East PD: The discovery and analysis of a diverged family of novel antifungal moricin-like peptides in the wax moth Galleria mellonella. Insect Biochem. Mol. Biol. 2008; 38:201-212. doi: 10.1016/j.ibmb.2007.10.009

[35] Gobbo M, Biondi L, Filira F, Gennaro R, Benincasa M, Scolaro B, Rocchi R: Antimicrobial peptides: synthesis and antibacterial activity of linear and cyclic drosocin and apidaecin $1 \mathrm{~b}$ analogues. J. Med. Chem. 2002; 45:4494-4504.

[36] Engström P, Carlsson A, Engström A, Tao ZJ, Bennich H: The antibacterial effect of attacins from the silk moth Hyalophora cecropia is directed against the outer membrane of Escherichia coli. EMBO J. 1984; 3:3347-3351.

[37] Bang K, Park S, Yoo JY, Cho S: Characterization and expression of attacin, an antibacterial protein-encoding gene, from the beet armyworm, Spodoptera exigua (Hübner) (Insecta: Lepidoptera: Noctuidae). Mol. Biol. Rep. 2012; 39:5151-5159. doi: 10.1007/ s11033-011-1311-3

[38] Hwang J, Kim Y: RNA interference of an antimicrobial peptide, gloverin, of the beet armyworm, Spodoptera exigua, enhances susceptibility to Bacillus thuringiensis. J. Invertebr. Pathol. 2011; 108:194-200. doi: 10.1016/j.jip.2011.09.003

[39] Xu XX, Zhong X, Yi HY, Yu XQ: Manduca sexta Gloverin binds microbial components and is active against bacteria and fungi. Dev. Comp. Immunol. 2012; 38:275-284. doi: 10.1016/j.dci.2012.06.012

[40] Axén A, Carlsson A, Engström A, Bennich H: Gloverin, an antibacterial protein from the immune hemolymph of Hyalophora pupae. Eur. J. Biochem. 1997; 247:614-619.

[41] Moreno-Habel DA, Biglang-awa IM, Dulce A, Luu DD, Garcia P, Weers PM, HaasStapleton EJ: Inactivation of the budded virus of Autographa californica M nucleopolyhedrovirus by gloverin. J. Invertebr. Pathol. 2012; 110:92-101. doi: 10.1016/j. jip.2012.02.007 
[42] Zhao HW, Zhou, Haddad GG: Antimicrobial peptides increase tolerance to oxidant stress in Drosophila melanogaster. J. Biol. Chem. 2011; 286:6211-6218. doi: 10.1074/jbc. M110.181206

[43] Gao B, Zhu S: The drosomycin multigene family: three-disulfide variants from Drosophila takahashii possess antibacterial activity. Sci. Rep. 2016; 6:32175. doi: 10.1038/srep32175

[44] Fehlbaum P, Bulet P, Michaut L, Lagueux M, Broekaert WF, Hetru C, Hoffmann JA: Insect immunity. Septic injury of Drosophila induces the synthesis of a potent antifungal peptide with sequence homology to plant antifungal peptides. J. Biol. Chem. 1994; 269:33159-33163.

[45] Zhang ZT, Zhu SY: Drosomycin, an essential component of antifungal defence in Drosophila. Insect Mol. Biol. 2009; 18:549-556. doi: 10.1111/j.1365-2583.2009.00907.x

[46] Tian C, Gao B, Rodriguez MdC, Lanz-Mendoza H, Ma B, Zhu S: Gene expression, antiparasitic activity, and functional evolution of the drosomycin family. Mol. Immunol. 2008; 45:3909-3916. doi: 10.1016/j.molimm.2008.06.025

[47] Levashina EA, Ohresser S, Bulet P, Reichhart JM, Hetru C, A HJ: Metchnikowin, a novel immune-inducible proline-rich peptide from Drosophila with antibacterial and antifungal properties. Eur. J. Biochem. 1995; 233:694-700.

[48] Levashina EA, Ohresser S, Lemaitre B, Imler JL: Two distinct pathways can control expression of the gene encoding the Drosophila antimicrobial peptide metchnikowin. J. Mol. Biol. 1998; 278:515-527. doi: 10.1006/jmbi.1998.1705

[49] Rahnamaeian M, Langen G, Imani J, Khalifa W, Altincicek B, von Wettstein D, Kogel KH, Vilcinskas A: Insect peptide metchnikowin confers on barley a selective capacity for resistance to fungal ascomycetes pathogens. J. Exp. Bot. 2009; 60:4105-4114. doi: 10.1093/ jxb/erp240

[50] Lemaitre B, Hoffmann JA: The host defense of Drosophila melanogaster. Annu. Rev. Immunol. 2007; 25:697-743. doi:10.1146/annurev.immunol.25.022106.141615

[51] Valanne S, Wang JH, Rämet M: The Drosophila Toll signaling pathway. J. Immunol. 2011; 186:649-656. doi: 10.4049/jimmunol.1002302

[52] Lindsay SA, Wasserman SA: Conventional and non-conventional Drosophila Toll signaling. Dev. Comp. Immunol. 2014; 42:16-24. doi: 10.1016/j.dci.2013.04.011

[53] Kleino A, Silverman N: The Drosophila IMD pathway in the activation of the humoral immune response. Dev. Comp. Immunol. 2014; 42:25-35. doi: 10.1016/j.dci.2013.05.014

[54] Myllymäki H, Valanne S, Rämet M: The Drosophila imd signaling pathway. J. Immunol. 2014; 192:3455-3462. doi: 10.4049/jimmunol.1303309

[55] Myllymäki H, Rämet M: JAK/STAT pathway in Drosophila immunity. Scand. J. Immunol. 2014; 79:377-385. doi: 10.1111/sji.12170

[56] Ashok Y: Drosophila toll pathway: the new model. Sci. Signal. 2009; 2:jc1. doi: 10.1126/ scisignal.252jc1 
[57] Bryant CE, Gay NJ, Heymans S, Sacre S, Schaefer L, Midwood KS: Advances in Toll-like receptor biology: modes of activation by diverse stimuli. Crit. Rev. Biochem. Mol. Biol. 2015; 50:359-379. doi: 10.3109/10409238.2015.1033511

[58] Kawasaki T, Kawai T: Toll-like receptor signaling pathways. Front. Immunol. 2014; 5:461. doi: 10.3389/fimmu.2014.00461

[59] Shia AK, Glittenberg M, Thompson G, Weber AN, Reichhart JM, Ligoxygakis P: Tolldependent antimicrobial responses in Drosophila larval fat body require Spätzle secreted by haemocytes. J. Cell Sci. 2009; 122:4505-4515. doi: 10.1242/jcs.049155

[60] Michel T, Reichhart JM, Hoffmann JA, Royet J: Drosophila Toll is activated by Grampositive bacteria through a circulating peptidoglycan recognition protein. Nature 2001; 414:756-759. doi: 10.1038/414756a

[61] Wang Y, Jiang H: Interaction of $\beta-1,3-$ Glucan with Its recognition protein activates hemolymph proteinase 14, an initiation enzyme of the prophenoloxidase activation system in Manduca sexta. J. Biol. Chem. 2006; 281:9271-9278. doi: 10.1074/jbc.M513797200

[62] Mishima Y, Quintin J, Aimanianda V, Kellenberger C, Coste F, Clavaud C, Hetru C, Hoffmann JA, Latgé JP, Ferrandon D et al.: The N-terminal domain of Drosophila Gramnegative binding protein 3 (GNBP3) defines a novel family of fungal pattern recognition receptors. J. Biol. Chem. 2009; 284:28687-28697. doi: 10.1074/jbc.M109.034587

[63] Gottar M, Gobert V, Matskevich AA, Reichhart JM, Wang C, Butt TM, Belvin M, Hoffmann JA, Ferrandon D: Dual detection of fungal infections in Drosophila via recognition of glucans and sensing of virulence factors. Cell 2006; 127:1425-1437. doi: 10.1016/j.cell.2006.10.046

[64] Imler JL, Hoffmann JA: Toll receptors in Drosophila: a family of molecules regulating development and immunity. Curr. Top. Microbiol. Immunol. 2002; 270:63-79.

[65] Tauszig-Delamasure S, Bilak H, Capovilla M, Hoffmann JA, Imler JL: Drosophila MyD88 is required for the response to fungal and Gram-positive bacterial infections. Nat. Immunol. 2002; 3:91-97. doi: 10.1038/ni747

[66] Lemaitre B, Kromer-Metzger E, Michaut L, Nicolas E, Meister M, Georgel P, Reichhart JM, Hoffmann JA: A recessive mutation, immune deficiency (imd), defines two distinct control pathways in the Drosophila host defense. Proc. Natl. Acad. Sci. U S A 1995; 92:9465-9469.

[67] Lemaitre B, Nicolas E, Michaut L, Reichhart JM, Hoffmann JA: The dorsoventral regulatory gene cassette spatzle/Toll/cactus controls the potent antifungal response in Drosophila adults. Cell 1996; 86:973-983.

[68] Kaneko T, N. S: Bacterial recognition and signalling by the Drosophila IMD pathway. Cell. Microbiol. 2005; 7:461-469. doi: 10.1111/j.1462-5822.2005.00504.x

[69] Kaneko T, Yano T, Aggarwal K, Lim JH, Ueda K, Oshima Y, Peach C, Erturk-Hasdemir D, Goldman WE, Oh BH et al.: PGRP-LC and PGRP-LE have essential yet distinct functions in the drosophila immune response to monomeric DAP-type peptidoglycan. Nat. Immunol. 2006; 7:715-723. doi: 10.1038/ni1356 
[70] Choe KM, Werner T, Stöven S, Hultmark D, Anderson KV: Requirement for a peptidoglycan recognition protein (PGRP) in Relish activation and antibacterial immune responses in Drosophila. Science 2002; 296:359-362. doi:10.1126/science.1070216

[71] Aggarwal K, Silverman N: Positive and negative regulation of the Drosophila immune response. BMB Rep. 2008; 41:267-277.

[72] Choe KM, Lee H, Anderson KV: Drosophila peptidoglycan recognition protein LC (PGRP-LC) acts as a signal-transducing innate immune receptor. Proc. Natl. Acad. Sci. U S A 2005; 102:1122-1126. doi: 10.1073/pnas.0404952102

[73] Leulier F, Vidal S, Saigo K, Ueda R, Lemaitre B: Inducible expression of double-stranded RNA reveals a role for $\mathrm{dFADD}$ in the regulation of the antibacterial response in Drosophila adults. Curr. Biol. 2002; 12:996-1000.

[74] Leulier F, Rodriguez A, Khush RS, Abrams JM, Lemaitre B: The Drosophila caspase Dredd is required to resist gram-negative bacterial infection. EMBO Rep. 2000; 1:353-358. doi: 10.1093/embo-reports/kvd073

[75] Paquette N, Broemer M, Aggarwal K, Chen L, Husson M, Ertürk-Hasdemir D, Reichhart JM, Meier P, Silverman N: Caspase-mediated cleavage, IAP binding, and ubiquitination: linking three mechanisms crucial for Drosophila NF-kB signaling. Mol. Cell 2010; 37:172-182. doi: 10.1016/j.molcel.2009.12.036

[76] Ertürk-Hasdemir D, Broemer M, Leulier F, Lane WS, Paquette N, Hwang D, Kim CH, Stöven S, Meier P, Silverman N: Two roles for the Drosophila IKK complex in the activation of Relish and the induction of antimicrobial peptide genes. Proc. Natl. Acad. Sci. U S A 2009; 106:9779-9784. doi: 10.1073/pnas.0812022106

[77] O'Shea J, Plenge R:JAK and STAT signaling molecules in immunoregulation and immunemediated disease. Immunity 2012; 36:542-550. doi: 10.1016/j.immuni.2012.03.014

[78] Kiu H, Nicholson SE: Biology and significance of the JAK/STAT signalling pathways. Growth Factors 2012; 30:88-106. doi: 10.3109/08977194.2012.660936

[79] Wright VM, Vogt KL, Smythe E, Zeidler MP: Differential activities of the Drosophila JAK/STAT pathway ligands Upd, Upd2 and Upd3. Cell. Signal. 2011; 23:920-927. doi: 10.1016/j.cellsig.2011.01.020

[80] Brown S, Hu N, Hombría JC: Identification of the first invertebrate interleukin JAK/STAT receptor, the Drosophila gene domeless. Curr. Biol. 2001; 11:1700-1705.

[81] Binari R, Perrimon N: Stripe-specific regulation of pair-rule genes by hopscotch, a putative Jak family tyrosine kinase in Drosophila. Genes Dev. 1994; 8:300-312.

[82] Yan R, Small S, Desplan C, Dearolf CR, Darnell JEJ: Identification of a Stat gene that functions in Drosophila development. Cell 1996; 84:421-430.

[83] Kishimoto T, Akira S, Narazaki M, Taga T: Interleukin-6 family of cytokines and gp130. Blood 1995; 86:1243-1254. 
[84] Starr R, Willson TA, Viney EM, Murray LJ, Rayner JR, Jenkins BJ, Gonda TJ, Alexander WS, Metcalf D, Nicola NA et al.: A family of cytokine-inducible inhibitors of signalling. Nature 1997; 387:917-921. doi: 10.1038/43206

[85] Kallio J, Myllymäki H, Grönholm J, Armstrong M, Vanha-aho LM, Mäkinen L, Silvennoinen O, Valanne S, Rämet M: Eye transformer is a negative regulator of Drosophila JAK/STAT signaling. FASEB J. 2010; 24:4467-4479. doi: 10.1096/ fj.10-162784

[86] Makki R, Meister M, Pennetier D, Ubeda JM, Braun A, Daburon V, Krzemień J, Bourbon HM, Zhou R, Vincent A et al.: A short receptor downregulates JAK/STAT signalling to control the Drosophila cellular immune response. PLoS Biol. 2010; 8:e1000441. doi: 10.1371/journal.pbio.1000441

[87] Callus B, Mathey-Prevot B: SOCS36E, a novel Drosophila SOCS protein, suppresses JAK/ STAT and EGF-R signalling in the imaginal wing disc. Oncogene 2002; 21:4812-4821. doi: 10.1038/sj.onc.1205618

[88] Ekengren S, Tryselius Y, Dushay MS, Liu G, Steiner H, Hultmark D: A humoral stress response in Drosophila. Curr. Biol. 2001; 11:714-718.

[89] Kemp C, Mueller S, Goto A, Barbier V, Paro S, Bonnay F, Dostert C, Troxler L, Hetru C, Meignin $C$ et al.: Broad RNA interference-mediated antiviral immunity and virus-specific inducible responses in Drosophila. J. Immunol. 2013; 190:650-658. doi: 10.4049/ jimmunol.1102486

[90] Buchon N, Broderick NA, Poidevin M, Pradervand S, Lemaitre B: Drosophila intestinal response to bacterial infection: activation of host defense and stem cell proliferation. Cell Host Microbe. 2009; 5:200-211. doi: 10.1016/j.chom.2009.01.003

[91] Buchon N, Silverman, Cherry S: Immunity in Drosophila melanogaster-from microbial recognition to whole-organism physiology. Nat. Rev. Immunol. 2014; 14:796-810. doi: 10.1038/nri3763

[92] Kurata S: Peptidoglycan recognition proteins in Drosophila immunity. Dev. Comp. Immunol. 2014; 42:36-41. doi: 10.1016/j.dci.2013.06.006

[93] Dziarski R, Gupta D: Mammalian PGRPs: novel antibacterial proteins. Cell. Microbiol. 2006; 8:1059-1069. doi: 10.1111/j.1462-5822.2006.00726.x

[94] Dziarski R, Gupta D: Review: Mammalian peptidoglycan recognition proteins (PGRPs) in innate immunity. Innate Immun. 2010; 16:168-174. doi: 10.1177/1753425910366059

[95] Charroux B, Rival T, Narbonne-Reveau K, Royet J: Bacterial detection by Drosophila peptidoglycan recognition proteins. Microbes Infect. 2009; 11:631-636. doi: 10.1016/j. micinf.2009.03.004

[96] Royet J, Gupta D, Dziarski R: Peptidoglycan recognition proteins: modulators of the microbiome and inflammation. Nat. Rev. Immunol. 2011; 11:837-851. doi: 10.1038/ nri3089 
[97] Steiner H: Peptidoglycan recognition proteins: on and off switches for innate immunity. Immunol. Rev. 2004; 198:83-96.

[98] Mellroth P, Steiner H: PGRP-SB1: an N-acetylmuramoyl L-alanine amidase with antibacterial activity. Biochem. Biophys. Res. Commun. 2006; 350:994-999. doi: 10.1016/j. bbrc.2006.09.139

[99] Pal S, Wu LP: Lessons from the fly: pattern recognition in Drosophila melanogaster. Adv, Exp. Med. Biol. 2009; 653:162-174.

[100] Jiang H, Ma C, Lu ZQ, Kanost MR: Beta-1,3-glucan recognition protein-2 (betaGRP-2) from Manduca sexta; an acute-phase protein that binds beta-1,3-glucan and lipoteichoic acid to aggregate fungi and bacteria and stimulate prophenoloxidase activation. Insect Biochem. Mol. Biol. 2004; 34:89-100.

[101] Wang Y, Sumathipala N, Rayaprolu S, Jiang H: Recognition of microbial molecular patterns and stimulation of prophenoloxidase activation by a $\beta-1,3$-glucanase-related protein in Manduca sexta larval plasma. Insect Biochem. Mol. Biol. 2011; 41:322-331. doi: 10.1016/j.ibmb.2011.01.010

[102] Pauchet Y, Freitak D, Heidel-Fischer HM, Heckel DG, Vogel H: Immunity or digestion: glucanase activity in a glucan-binding protein family from Lepidoptera. J. Biol. Chem. 2009; 284:2214-2224. doi:10.1074/jbc.M806204200

[103] Rosales C, O'Brien V, Kornberg L, Juliano RL: Signal transduction by cell adhesion receptors. Biochim. Biophys. Acta 1995; 1242:77-98.

[104] Gandhe AS, Arunkumar KP, John SH, Nagaraju J: Analysis of bacteria-challenged wild silkmoth, Antheraea mylitta (lepidoptera) transcriptome reveals potential immune genes. BMC Genomics. 2006; 7:184. doi: 10.1186/1471-2164-7-184

[105] Eum JH, Seo YR, Yoe SM, Kang SW, Han SS: Analysis of the immune-inducible genes of Plutella xylostella using expressed sequence tags and cDNA microarray. Dev. Comp. Immunol. 2007; 31:1107-1120. doi: 10.1016/j.dci.2007.02.002

[106] Bao Y, Yamano Y, Morishima I: Induction of hemolin gene expression by bacterial cell wall components in eri-silkworm, Samia cynthia ricini. Comp. Biochem. Physiol. Part B. Biochem. Mol. Biol. 2007; 146:147-151. doi: 10.1016/j.cbpb.2006.10.092

[107] Eleftherianos I, Gökçen F, Felföldi G, Millichap PJ, Trenczek TE, ffrench-Constant RH, Reynolds SE: The immunoglobulin family protein Hemolin mediates cellular immune responses to bacteria in the insect Manduca sexta. Cell. Microbiol. 2007; 9:1137-1147. doi: 10.1111/j.1462-5822.2006.00855.x

[108] Yu X-Q, Kanost MR: Immulectin-2, a Lipopolysaccharide-specific lectin from an insect, Manduca sexta, is induced in response to Gram-negative bacteria. J. Biol. Chem. 2000; 275:37373-37381. doi:10.1074/jbc.M003021200

[109] Yu XQ, Ling E, Tracy ME, Zhu Y: Immulectin-4 from the tobacco hornworm Manduca sexta binds to lipopolysaccharide and lipoteichoic acid. Insect Mol. Biol. 2006; 15:119128. doi: 10.1111/j.1365-2583.2006.00618.x 
[110] Watanabe A, Miyazawa S, Kitami M, Tabunoki H, Ueda K, Sato R: Characterization of a novel C-type lectin, Bombyx mori multibinding protein, from the B. mori hemolymph: mechanism of wide-range microorganism recognition and role in immunity. J. Immunol. 2006; 177:4594-4604.

[111] Shin SW, Park DS, Kim SC, Park HY: Two carbohydrate recognition domains of Hyphantria cunea lectin bind to bacterial lipopolysaccharides through O-specific chain. FEBS Lett. 2000; 467:70-74.

[112] Schmid-Hempel P: Evolutionary ecology of insect immune defenses. Annu. Rev. Entomol. 2005; 50:529-551. doi: 10.1146/annurev.ento.50.071803.130420

[113] Garcia-Garcia E, Garcia-Garcia PL, Rosales C: An fMLP receptor is involved in activation of phagocytosis by hemocytes from specific insect species. Dev. Comp. Immunol. 2009; 33:728-739. doi: 10.1016/j.dci.2008.12.006

[114] Gardiner EM, Strand MR: Monoclonal antibodies bind distinct classes of hemocytes in the moth Pseudoplusia includens. J. Insect Physiol. 1999; 45:113-126.

[115] Nardi JB, Pilas B, Bee CM, Zhuang S, Garsha K, Kanost MR: Neuroglian-positive plasmatocytes of Manduca sexta and the initiation of hemocyte attachment to foreign surfaces. Dev. Comp. Immunol. 2006; 30:447-462. doi: 10.1016/j.dci.2005.06.026

[116] Wiegand C, Levin D, Gillespie J, Willott E, Kanost M, Trenczek T: Monoclonal antibody MS13 identifies a plasmatocyte membrane protein and inhibits encapsulation and spreading reactions of Manduca sexta hemocytes. Arch. Insect Biochem. Physiol. 2000; 45:95-108. doi: 10.1002/1520-6327(200011)45:3<95::AID-ARCH1>3.0.CO;2-0

[117] Zhang S, Clark KD, Strand MR: The protein P23 identifies capsule-forming plasmatocytes in the moth Pseudoplusia includens. Dev. Comp. Immunol. 2011; 35:501-510. doi: 10.1016/j.dci.2010.12.006

[118] Parsons B, Foley E: Cellular immune defenses of Drosophila melanogaster. Dev. Comp. Immunol. 2016; 58:95-101. doi: 10.1016/j.dci.2015.12.019

[119] Crozatier M, Meister M: Drosophila haematopoiesis. Cell. Microbiol. 2007; 9:1117-1126. doi: 10.1111/j.1462-5822.2007.00930.x

[120] Hillyer JF: Insect immunology and hematopoiesis. Dev. Comp. Immunol. 2016; 58:102118. doi: 10.1016/j.dci.2015.12.006

[121] Honti V, Csordas G, Kurucz E, Markus R, Ando I: The cell-mediated immunity of Drosophila melanogaster: hemocyte lineages, immune compartments, microanatomy and regulation. Dev. Comp. Immunol. 2014; 42:47-56. doi: 10.1016/j.dci.2013.06.005

[122] Wood W, Faria C, Jacinto A: Distinct mechanisms regulate hemocyte chemotaxis during development and wound healing in Drosophila melanogaster. J. Cell Biol. 2006; 173:405-416. doi: 10.1083/jcb.200508161

[123] Nagaosa K, Okada R, Nonaka S, Takeuchi K, Fujita Y, Miyasaka T, Manaka J, Ando I, Nakanishi Y: Integrin $\beta v$-mediated phagocytosis of apoptotic cells in Drosophila embryos. J. Biol. Chem. 2011; 286:25770-25777. doi:10.1074/jbc.M110.204503 
[124] Stofanko M, Kwon SY, Badenhorst P: Lineage tracing of lamellocytes demonstrates Drosophila macrophage plasticity. PLoS One 2010; 5:e14051. doi: 10.1371/journal. pone.0014051

[125] Shaukat Z, Liu D, Gregory S: Sterile inflammation in Drosophila. Mediators Inflamm. 2015; 2015:369286. doi: 10.1155/2015/369286

[126] Markus R, Kurucz E, Rus F, Ando I: Sterile wounding is a minimal and sufficient trigger for a cellular immune response in Drosophila melanogaster. Immunol. Lett. 2005; 101:108111. doi: 10.1016/j.imlet.2005.03.021

[127] Schmidt O, Söderhäll K, Theopold U, Faye I: Role of adhesion in arthropod immune recognition. Annu. Rev. Entomol. 2010; 55:485-504. doi: 10.1146/annurev. ento.54.110807.090618

[128] Ratheesh A, Belyaeva V, Siekhaus DE: Drosophila immune cell migration and adhesion during embryonic development and larval immune responses. Curr. Opin. Cell Biol. 2015; 36:71-79. doi: 10.1016/j.ceb.2015.07.003

[129] Rosales C: Phagocytosis, a cellular immune response in insects. Inv. Surv. J. 2011; 8:109-131.

[130] Castillo JC, Robertson AE, Strand MR: Characterization of hemocytes from the mosquitoes Anopheles gambiae and Aedes aegypti. Insect Biochem. Mol. Biol. 2006; 36:891903. doi: 10.1016/j.ibmb.2006.08.010

[131] Lamprou I, Mamali I, Dallas K, Fertakis V, Lampropoulou M, Marmaras VJ: Distinct signalling pathways promote phagocytosis of bacteria, latex beads and lipopolysaccharide in medfly haemocytes. Immunology 2007; 121:314-327. doi: 10.1111/j.1365-2567.2007.02576.x

[132] Franc NC, Dimarcq JL, Lagueux M, Hoffmann J, Ezekowitz RA: Croquemort, a novel Drosophila hemocyte/macrophage receptor that recognizes apoptotic cells. Immunity 1996; 4:431-443.

[133] Manaka J, Kuraishi T, Shiratsuchi A, Nakai Y, Higashida H, Henson P, Nakanishi Y: Draper-mediated and phosphatidylserine-independent phagocytosis of apoptotic cells by Drosophila hemocytes/macrophages. J. Biol. Chem. 2004; 279:48466-48476. doi: 10.1074/jbc.M408597200

[134] Vlisidou I, Dowling AJ, Evans IR, Waterfield N, ffrench-Constant RH, Wood W: Drosophila embryos as model systems for monitoring bacterial infection in real time. PLoS Pathog. 2009; 5:e1000518. doi: 10.1371/journal.ppat.1000518

[135] Kocks C, Cho JH, Nehme N, Ulvila J, Pearson AM, Meister M, Strom C, Conto SL, Hetru C, Stuart LM et al.: Eater, a transmembrane protein mediating phagocytosis of bacterial pathogens in Drosophila. Cell 2005; 123:335-346. doi: 10.1016/j.cell.2005.08.034

[136] Kurucz E, Márkus R, Zsámboki J, Folkl-Medzihradszky K, Darula Z, Vilmos P, Udvardy A, Krausz I, Lukacsovich T, Gateff E et al.: Nimrod, a putative phagocytosis 
receptor with EGF repeats in Drosophila plasmatocytes. Curr. Biol. 2007; 17:649-654. doi: 10.1016/j.cub.2007.02.041

[137] Nakatogawa S, Oda Y, Kamiya M, Kamijima T, Aizawa T, Clark KD, Demura M, Kawano K, Strand MR, Hayakawa Y: A novel peptide mediates aggregation and migration of hemocytes from an insect. Curr. Biol. 2009; 19:779-785. doi: 10.1016/j. cub.2009.03.050

[138] Strand MR: The insect cellular immune response. Insect Science 2008; 15:1-14.

[139] Shrestha S, Kim YJ: Various eicosanoids modulate the cellular and humoral immune responses of the beet armyworm, Spodoptera exigua. Biosci. Biotechnol. Biochem. 2009; 73:2077-2084. doi: 10.1271/bbb.90272

[140] Shrestha S, Park Y, Stanley D, Kim Y: Genes encoding phospholipases A2 mediate insect nodulation reactions to bacterial challenge. J. Insect Physiol. 2010; 56:324-332. doi: 10.1016/j.jinsphys.2009.11.008

[141] Stanley D, Miller J, Tunaz H: Eicosanoid actions in insect immunity. J. Innate Immun. 2009; 1:282-290. doi: 10.1159/000210371

[142] Zhao F, Stanley D, Wang Y, Zhu F, Lei CL: Eicosanoids mediate nodulation reactions to a mollicute bacterium in larvae of the blowfly, Chrysomya megacephala. J. Insect Physiol. 2009; 55:192-196. doi: 10.1016/j.jinsphys.2008.10.018

[143] Gandhe AS, John SH, Nagaraju J: Noduler, a novel immune up-regulated protein mediates nodulation response in insects. J. Immunol. 2007; 179:6943-6951.

[144] Bao YY, Xue J, Wu WJ, Wang Y, Lv ZY, Zhang CX: An immune-induced reeler protein is involved in the Bombyx mori melanization cascade. Insect Biochem. Mol. Biol. 2011; 41:696-706. doi: 10.1016/j.ibmb.2011.05.001

[145] Ling E, Yu XQ: Cellular encapsulation and melanization are enhanced by immulectins, pattern recognition receptors from the tobacco hornworm Manduca sexta. Dev. Comp. Immunol. 2006; 30:289-299. doi: 10.1016/j.dci.2005.05.005

[146] Carton Y, Frey F, Nappi AJ: Parasite-induced changes in nitric oxide levels in Drosophila paramelanica. J. Parasitol. 2009; 95:1134-1141. doi: 10.1645/GE-2091.1

[147] Rosales C: Fc receptor and integrin signaling in phagocytes. Signal Transduction 2007; 7:386-401.

[148] Zhuang S, Kelo L, Nardi JB: Multiple $\alpha$ subunits of integrin are involved in cell-mediated responses of the Manduca immune system. Dev. Comp. Immunol. 2008; 32:365379. doi: 10.1016/j.dci.2007.07.007

[149] Irving P, Ubeda JM, Doucet D, Troxler L, Lagueux M, Zachary D, Hoffmann JA, Hetru C, Meister M: New insights into Drosophila larval haemocyte functions through genome-wide analysis. Cell Microbiol. 2005; 7:335-350. 
[150] Altincicek B, Stotzel S, Wygrecka M, Preissner KT, Vilcinskas A: Host-derived extracellular nucleic acids enhance innate immune responses, induce coagulation, and prolong survival upon infection in insects. J. Immunol. 2008; 181:2705-2712.

[151] Branzk N, Papayannopoulos V: Molecular mechanisms regulating NETosis in infection and disease. Semin. Immunopathol. 2013; 35:513-530. doi: 10.1007/s00281-013-0384-6

[152] Brinkmann V, Zychlinsky A: Neutrophil extracellular traps: is immunity the second function of chromatin? J. Cell Biol. 2012; 198:773-783. doi: 10.1083/jcb.201203170

[153] Robb CT, Dyrynda EA, Gray RD, Rossi AG, Smith VJ: Invertebrate extracellular phagocyte traps show that chromatin is an ancient defence weapon. Nat. Commun. 2014; 5:4627. doi: $10.1038 /$ ncomms5627

[154] Nappi A, Poirié M, Carton Y: The role of melanization and cytotoxic by-products in the cellular immune responses of Drosophila against parasitic wasps. Adv. Parasitol. 2009; 70:99-121. doi: 10.1016/S0065-308X(09)70004-1

[155] Eleftherianos I, Revenis C: Role and importance of phenoloxidase in insect hemostasis. J. Innate Immun. 2011; 3:28-33. doi: 10.1159/000321931

[156] Krem MM, Di Cera E: Evolution of enzyme cascades from embryonic development to blood coagulation. Trends Biochem. Sci. 2002; 27:67-74.

[157] Ling E, Yu XQ: Prophenoloxidase binds to the surface of hemocytes and is involved in hemocyte melanization in Manduca sexta. Insect Biochem. Mol. Biol. 2005; 35:13561366. doi: 10.1016/j.ibmb.2005.08.007

[158] AliyariR,DingSW:RNA-basedviralimmunityinitiated by theDicerfamilyofhostimmune receptors. Immunol. Rev. 2009; 227:176-188. doi: 10.1111/j.1600-065X.2008.00722.x

[159] Bernstein E, Caudy AA, Hammond SM, Hannon GJ: Role of a bidentate ribonuclease in the initiation step of RNA interference. Nature 2001; 409:363-366. doi: 10.1038/35053110

[160] Liu Q, Rand TA, Kalidas S, Du F, Kim H-E, Smith DP, Wang X: R2D2, a bridge between the initiation and effector steps of the Drosophila RNAi pathway. Science 2003; 301:19211925. doi: $10.1126 /$ science. 1088710

[161] Okamura K, Chung WJ, Ruby JG, Guo H, Bartel DP, Lai EC: The Drosophila hairpin RNA pathway generates endogenous short interfering RNAs. Nature 2008; 453:803806. doi: 10.1038/nature07015

[162] Rand TA, Ginalski K, Grishin NV, Wang X: Biochemical identification of Argonaute 2 as the sole protein required for RNA-induced silencing complex activity. Proc. Natl. Acad. Sci. U S A 2004; 101:14385-14389. doi: 10.1073/pnas.0405913101

[163] Aliyari R, Wu Q, Li HW, Wang XH, Li F, Green LD, Han CS, Li WX, Ding SW: Mechanism of induction and suppression of antiviral immunity directed by virusderived small RNAs in Drosophila. Cell Host Microbe. 2008; 4:387-397. doi: 10.1016/j. chom.2008.09.001 
[164] Nayak A, Berry B, Tassetto M, Kunitomi M, Acevedo A, Deng C, Krutchinsky A, Gross J, Antoniewski C, Andino R: Cricket paralysis virus antagonizes Argonaute 2 to modulate antiviral defense in Drosophila. Nat. Struct. Mol. Biol. 2010; 17:547-554. doi: 10.1038/nsmb.1810

[165] Lingel A, Simon B, Izaurralde E, Sattler M: The structure of the Flock House virus B2 protein, a viral suppressor of RNA interference, shows a novel mode of double-stranded RNA recognition. EMBO Rep. 2005; 6:1149-1155. doi: 10.1038/sj.embor.7400583

[166] Kakumani PK, Ponia SS, S RK, Sood V, Chinnappan M, Banerjea AC, Medigeshi GR, Malhotra P, Mukherjee SK, Bhatnagar RK: Role of RNA interference (RNAi) in dengue virus replication and identification of NS4B as an RNAi suppressor. J. Virol. 2013; 87:8870-8883. doi: 10.1128/JVI.02774-12

[167] Zambon RA, Nandakumar M, Vakharia VN, Wu LP: The Toll pathway is important for an antiviral response in Drosophila. Proc. Natl. Acad. Sci. U S A 2005; 102:7257-7262. doi: 10.1073/pnas.0409181102

[168] Xi Z, Ramirez JL, Dimopoulos G: The Aedes aegypti toll pathway controls dengue virus infection. PLoS Pathog. 2008; 4:e1000098. doi: 10.1371/journal.ppat.1000098

[169] Avadhanula V, Weasner BP, Hardy GG, Kumar JP, Hardy RW: A novel system for the launch of alphavirus RNA synthesis reveals a role for the Imd pathway in arthropod antiviral response. PLoS Pathog. 2009; 5:e1000582. doi: 10.1371/journal.ppat.1000582

[170] Costa A, Jan E, Sarnow P, Schneider D: The Imd pathway is involved in antiviral immune responses in Drosophila. PLoS One 2009; 4:e7436. doi: 10.1371/journal.pone.0007436

[171] Hedges LM, Johnson KN: Induction of host defence responses by Drosophila C virus. J. Gen. Virol. 2008; 89:1497-1501. doi: 10.1099/vir.0.83684-0

[172] Souza-Neto JA, Sim S, Dimopoulos G: An evolutionary conserved function of the JAKSTAT pathway in anti-dengue defense. Proc. Natl. Acad. Sci. U S A 2009; 106:1784117846 doi: 10.1073/pnas.0905006106

[173] Paradkar PN, Trinidad L, Voysey R, Duchemin JB, Walker PJ: Secreted Vago restricts West Nile virus infection in Culex mosquito cells by activating the Jak-STAT pathway. Proc. Natl. Acad. Sci. U S A 2012; 109:18915-18920. doi: 10.1073/pnas.1205231109

[174] Lamiable O, Imler JL: Induced antiviral innate immunity in Drosophila. Curr. Opin. Microbiol. 2014; 20:62-68. doi: 10.1016/j.mib.2014.05.006

[175] Deddouche S, Matt N, Budd A, Mueller S, Kemp C, Galiana-Arnoux D, Dostert C, Antoniewski C, Hoffmann JA, Imler JL: The DExD/H-box helicase Dicer-2 mediates the induction of antiviral activity in Drosophila. Nat. Immunol. 2008; 9:1425-1432. doi: 10.1038/ni.1664

[176] Kingsolver MB, Huang Z, Hardy RW: Insect antiviral innate immunity: pathways, effectors, and connections. J. Mol. Biol. 2013; 425:4921-4936. doi: 10.1016/j.jmb.2013.10.006 
[177] Nakamoto M, Moy R, Xu J, Bambina S, Yasunaga A, Shelly SS, Gold B, Cherry S: Virus recognition by Toll-7 activates antiviral autophagy in Drosophila. Immunity 2012; 36:658-667. doi: 10.1016/j.immuni.2012.03.003

[178] Shelly S, Lukinova N, Bambina S, Berman A, Cherry S: Autophagy is an essential component of Drosophila immunity against vesicular stomatitis virus. Immunity 2009; 30:588-598. doi: 10.1016/j.immuni.2009.02.009

[179] Kuma A, Mizushima N: Physiological role of autophagy as an intracellular recycling system: with an emphasis on nutrient metabolism. Semin. Cell Dev. Biol. 2010; 21:683690. doi: 10.1016/j.semcdb.2010.03.002

[180] Stephan JS, Herman P: The regulation of autophagy in eukaryotic cells: do all roads pass through Atg1? Autophagy 2006; 2:146-148.

[181] Mizushima N: The role of the Atg1/ULK1 complex in autophagy regulation. Curr. Opin. Cell Biol. 2010; 22:132-139. doi: 10.1016/j.ceb.2009.12.004

[182] Pham LN, Dionne MS, Shirasu-Hiza M, Schneider DS: A specific primed immune response in Drosophila is dependent on phagocytes. PLoS Pathog. 2007; 3:1-8. doi: 10.1371/journal.ppat.0030026 